\title{
Decorated ultrathin bismuth selenide nanosheets as targeted theranostic agents for in vivo imaging guided cancer radiation therapy
}

\author{
Zhenhuan Song ${ }^{1}$, Yanzhou Chang ${ }^{1}$, Hanhan $\mathrm{Xie}^{2}$, Xue-Feng $\mathrm{Yu}^{2}$, Paul $\mathrm{K} \mathrm{Chu}^{3}$ and Tianfeng Chen ${ }^{1}$ \\ An efficient radiotherapeutic agent is synthesized using ultrathin two-dimensional 30-nm-wide and 2-nm-thick $\mathrm{Bi}_{2} \mathrm{Se}_{3}$ \\ nanosheets (NSs) as a radiosensitizer. Chitosan (CS) and RGD peptide are employed to enhance the radiotherapy efficiency \\ and biocompatibility. The $\mathrm{Bi}_{2} \mathrm{Se}_{3}$-CS-RGD NSs exhibit excellent targeting ability to $\alpha v \beta 3$ integrin-overexpressing cancer cells and \\ potent radiosensitization efficiency with high stability. Detailed in vitro experiments show that the $\mathrm{Bi}_{2} \mathrm{Se}_{3}-\mathrm{CS}-\mathrm{RGD}$ NSs enhance \\ the sensitivity of HeLa cells to X-ray-induced cell death by inhibiting TrxR activities and activating downstream reactive oxygen \\ species-mediated signaling pathways. In vivo experiments using intravenous or intratumor injection demonstrate that the $\mathrm{Bi}_{2} \mathrm{Se}_{3^{-}}$ \\ CS-RGD NSs are more efficient tumor growth inhibitors compared to bare $\mathrm{Bi}_{2} \mathrm{Se}_{3} \mathrm{NSs}$. The multifunctionality of the NSs enables \\ the use of photoacoustic imaging and magnetic resonance imaging to examine their targeting ability and therapeutic effects, \\ respectively. In addition, the RGD-decorated $\mathrm{Bi}_{2} \mathrm{Se}_{3} \mathrm{NSs}$ show much better in vivo biocompatibility and can be efficiently \\ expelled from the body after $48 \mathrm{~h}$ post injection. This study reveals an effective and safe theranostic agent for next-generation \\ cancer radiotherapy.
}

NPG Asia Materials (2017) 9, e439; doi:10.1038/am.2017.167; published online 27 October 2017

\section{INTRODUCTION}

In addition to surgery and chemotherapy, radiotherapy is an important treatment in cancer therapy that is suitable for breast, ${ }^{1,2}$ cervical, ${ }^{3}$ lung $^{4-6}$ and brain ${ }^{7,8}$ cancers. Despite recent efforts, radiotherapy fails to fully eradicate tumors due to inevitable damage to surrounding healthy tissues and the radiation insensitivity of some tumors. Hence, various chemical radiosensitizers have been suggested to accentuate the effects of radiation therapy. For example, 'electronaffinic' nitroaromatic compounds as hypoxic-specific cytotoxins, ${ }^{9,10}$ and pyrimidines substituted with bromine or iodine can be incorporated into DNA to enhance free radical damage. ${ }^{11}$ Morever, it has been reported that pentoxifylline can improve tumor oxygenation and radiation responses. ${ }^{12}$ However, few radiosensitizers are available on the market due to the difficulty and high cost of large-scale production; thus, development of new radiotherapy agents is of scientific and clinical interest.

In recent years, high- $Z$ (high atomic number) nanomaterials with enhanced photoelectric and Compton effects have aroused interest, especially from the perspective of enhancing the therapeutic efficiency and specificity of radiotherapy. High-Z elements with larger X-ray interaction cross-sections than light elements (for example, $\mathrm{H}, \mathrm{O}, \mathrm{N}$ and $\mathrm{C}$ ) could increase the energy deposition and radiolytic hydrolysis in the vicinity of the materials. ${ }^{2}$ Several high- $Z$ materials, such as germanium nanoparticles (NPs), ${ }^{13}$ iron oxide NPs, ${ }^{14,15}$ lanthanidebased compounds, ${ }^{16}$ iodine, ${ }^{17}$ gold-based NPs ${ }^{18}$ and nuclear-targeting gadolinium-based NPs, ${ }^{19}$ have recently been used as adjuvants to enhance cellular radiosensitivity. However, few are efficient in in vivo cancer radiotherapy. The ideal radiotherapeutic nanoagent should have high radiosensitization and radio-stability, suitable size and proper surface functionalization to prolong the circulation lifetime and facilitate efficient tumor targeting. The additional imaging ability rendered by the agent can provide real-time information to guide procedures, monitor the therapeutic response, and treat diseases with greater specificity and sensitivity.

Selenium (Se) is an essential and unique trace element that provides effective prevention against serious diseases, such as cancers, inflammation and cardiovascular disease, and may therefore open up new horizons in disease treatment. ${ }^{20-22}$ SeNPs can be employed in nanocarriers for drug delivery and therapeutic agents due to their excellent bioavailability, low toxicity and significant radiosensitization effects with X-ray irradiation. ${ }^{23-25}$ Selenadiazole derivatives and Se-containing $\mathrm{Ru}$ complexes have been designed to combine radiotherapy and chemotherapy in vitro and in vivo due to their surface plasmon resonance effect and high refractive index, which facilitate light absorption. ${ }^{26-28}$ As new responsive materials for use in combination radiotherapy and chemotherapy, diselenide-containing polymers

\footnotetext{
${ }^{1}$ Department of Chemistry, Jinan University, Guangzhou, China; ${ }^{2}$ Institute of Biomedicine and Biotechnology, Shenzhen Institutes of Advanced Technology, Chinese Academy of Sciences, Shenzhen, China and ${ }^{3}$ Department of Physics and Materials Science, City University of Hong Kong, Kowloon, Hong Kong, China Correspondence: Professor X-F Yu, Institute of Biomedicine and Biotechnology, Shenzhen Institutes of Advanced Technology, Chinese Academy of Sciences, Shenzhen 518055, China.

E-mail: xf.yu@siat.ac.cn

or Professor T Chen, Department of Chemistry, Jinan University, Guangzhou 510632, China.

E-mail: tchentf@jnu.edu.cn

Received 25 February 2017; revised 2 June 2017; accepted 14 June 2017
} 


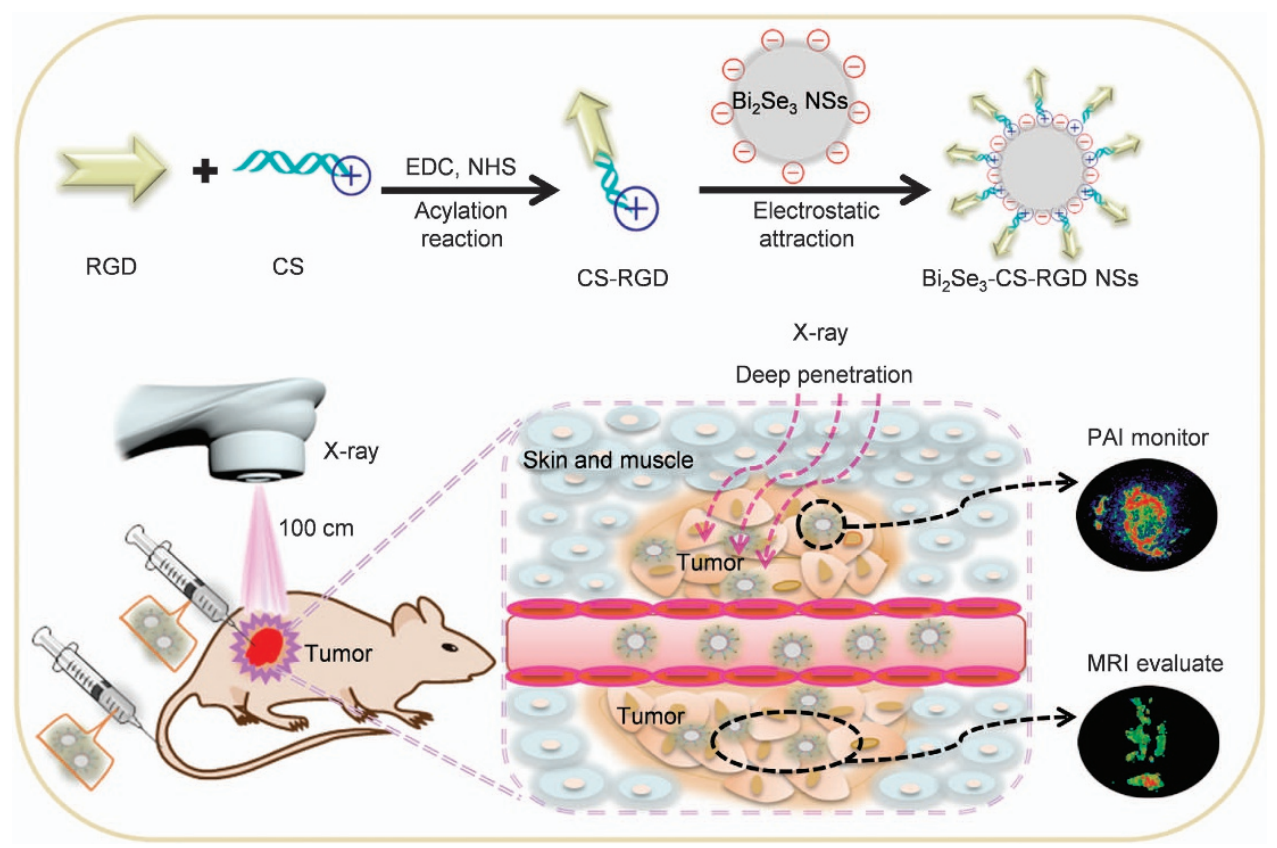

Scheme 1 Schematic illustration of the rational design of $\mathrm{Bi}_{2} \mathrm{Se}_{3}-\mathrm{CS}-\mathrm{RGD}$ NSs as a targeted theranostic agent for in vivo imaging-guided cancer radiation therapy.

have proven to be more sensitive to a low dose of $\gamma$-radiation than similar disulfides because the bond energy of Se-Se $\left(172 \mathrm{~kJ} \mathrm{~mol}^{-1}\right)$ is weaker than that of the S-S bond $\left(240 \mathrm{~kJ} \mathrm{~mol}^{-1}\right){ }^{29,30}$ In addition to the potential use of ultrasmall selenide NPs in photoacoustic imaging (PAI) and photothermal therapy, the large X-ray attenuation coefficients of Se elements for low-energy X-rays $\left(\mu=48.18 \mathrm{~cm}^{2} \mathrm{~g}^{-1}\right.$ at $20 \mathrm{keV}$ ) highlight their potential in X-ray computed tomography (CT) imaging, whereas sulfides do not exhibit this beneficial effect. ${ }^{31}$ These examples clearly illustrate the huge potential of selenide in chemo-/ radiotherapy and in multimodal imaging-guided synergistic therapy against cancer. Notably, the valence of selenium may not influence the treatment effect for cancer.

$\mathrm{Bi}$ is a high- $Z$ element $(Z=83)$, and its $\mathrm{X}$-ray attenuation coefficient is larger than those of $\mathrm{I}, \mathrm{Au}$, and Pt. Therefore, several Bi-based nanomaterials, such as $\mathrm{Bi}_{2} \mathrm{~S}_{3}$ nanodots, ${ }^{32} \mathrm{Bi}_{2} \mathrm{~S}_{3}$ nanorods ${ }^{33}$ and $\mathrm{Bi}_{2} \mathrm{Se}_{3}$ NPs with different morphologies, ${ }^{34-38}$ have been proposed as X-ray CT contrast agents and radio-/photothermal therapy sensitizing agents. Compared with orthorhombic $\mathrm{Bi}_{2} \mathrm{~S}_{3}$, the topological insulator $\mathrm{Bi}_{2} \mathrm{Se}_{3}$ has a two-dimensional layered rhombohedral structure with a unique surface electronic state $\mathrm{s}^{39,40}$ and has aroused increasing interest in biomedical applications due to its multifunctionality and good biocompatibility. ${ }^{41}$ Notably, $\mathrm{Bi}_{2} \mathrm{Se}_{3}$ nanostructures can release vital selenium for reducing the occurrence and fatality of liver, prostate, and lung cancers compared with nanoscale $\mathrm{Bi}_{2} \mathrm{~S}_{3} \cdot{ }^{42}$ It has recently been reported that two-dimensional 53.8-nm-wide and 6-nm-thick $\mathrm{Bi}_{2} \mathrm{Se}_{3}$ nanosheets (NSs) can inhibit tumor growth under X-ray irradiation and are metabolizable. ${ }^{41}$ These studies demonstrate the great potential of $\mathrm{Bi}_{2} \mathrm{Se}_{3}$ as an $\mathrm{X}$-ray radiosensitizer in clinical use. However, the research in this area is still in the initial stages. In clinical applications, the primary concern for the agents is the selectivity for tumor tissue to avoid radiosensitization of adjacent normal tissue. However, bare $\mathrm{Bi}_{2} \mathrm{Se}_{3}$ without the active tumor-targeting ability may increase the risk of radiation injury in normal tissues, and its instability and high passive uptake may damage organs. Furthermore, the anticancer mechanism of $\mathrm{Bi}_{2} \mathrm{Se}_{3}$ has not yet been explored.
In this work, decorated ultrathin $\mathrm{Bi}_{2} \mathrm{Se}_{3}$-CS-RGD NSs $(30 \mathrm{~nm}$ wide and $2 \mathrm{~nm}$ thick) are designed and produced as a targeted theranostic agent for in vivo imaging-guided cancer radiotherapy. The design and synthesis protocol of the agent are shown in Scheme 1. Briefly, the RGD peptide, which has an excellent targeted ability to $\alpha v \beta 3$ integrin, is conjugated with chitosan (CS) by forming the amido linkage, and the CS-RGD complex is combined with the $\mathrm{Bi}_{2} \mathrm{Se}_{3} \mathrm{NSs}$ by electrostatic interaction. The $\mathrm{Bi}_{2} \mathrm{Se}_{3}$-CS-RGD NSs demonstrate good stability in the biological environment even under X-ray irradiation. Detailed in vitro experiments are conducted to investigate the anticancer mechanism of the NS-based X-ray radiotherapy. In vivo experiments are also performed to evaluate the applicability of imaging-guided radiotherapy, radiosensitization effects, and in vivo toxicity of the $\mathrm{Bi}_{2} \mathrm{Se}_{3}$ and $\mathrm{Bi}_{2} \mathrm{Se}_{3}$-CS-RGD NSs by either intravenous or intratumor injection. To simulate real clinical conditions, all the radiation experiments are performed using an Elekta Precise linear accelerator $(6 \mathrm{MeV}$ energy, $5 \mathrm{~cm}$ penetration, $100 \mathrm{MU}$ ) in a hospital.

\section{MATERIALS AND METHODS}

\section{Synthesis of $\mathrm{Bi}_{2}$ Se-CS-RGD NSs}

The $\mathrm{Bi}_{2} \mathrm{Se}_{3}$ NSs were synthesized according to a previously published method. ${ }^{43}$ Briefly, the $\mathrm{Bi}_{2} \mathrm{Se}_{3}$ NSs were prepared by reacting $\mathrm{Bi}\left(\mathrm{NO}_{3}\right)_{3} \cdot 5 \mathrm{H}_{2} \mathrm{O}$ with a NaHSe solution. The solution contained ethylene glycol (EG) $(32.5 \mathrm{ml})$, $\mathrm{Bi}\left(\mathrm{NO}_{3}\right)_{3} \cdot 5 \mathrm{H}_{2} \mathrm{O}(0.226 \mathrm{~g})$ and polyvinylpyrrolidone (PVP) $(0.5 \mathrm{~g})$ as a surfactant. The reaction proceeded by rapid injection of the freshly synthesized oxygen-free NaHSe solution $\left(0.667 \mathrm{~mol} \mathrm{l}^{-1}, 1.048 \mathrm{ml}\right)$ at $160^{\circ} \mathrm{C}$. The reaction mixture immediately turned dark due to the formation of $\mathrm{Bi}_{2} \mathrm{Se}_{3} \mathrm{NSs}$. The reaction proceeded for $10 \mathrm{~min}$ before cooling to room temperature. The $\mathrm{Bi}_{2} \mathrm{Se}_{3}$-CS NSs were synthesized by conjugating RGD to CS via the formation of amido linkages in the N-hydroxysuccinimide (NHS)/1-ethyl-3-[3-(dimethylamino)- propyl]carbodiimide hydrochloride (EDC) reaction system. The CS and $\mathrm{Bi}_{2} \mathrm{Se}_{3} \mathrm{NSs}$ were combined by electrostatic interaction. The crude product was purified by dialysis in Milli-Q water for $24 \mathrm{~h}$ until no Bi could be detected from the outer solution using ICP-AES (OPTIMA 2100 DV, Waltham, MA USA). 


\section{Characterization}

The morphology of the samples was examined by transmission electron microscopy (Hitachi H-7650, $80 \mathrm{kV}$, Tokyo, Japan) and high-resolution transmission electron microscopy (JEOL 2010, $200 \mathrm{kV}$, Tokyo, Japan). Atomic force microscopy (AFM) was conducted on drop-cast flakes on $\mathrm{Si} / \mathrm{SiO}_{2}$ substrates using an MFP-3D-S atomic force microscope (Asylum Research, USA) with the AC mode (tapping mode) in air. Powder X-ray diffraction (XRD) was conducted using an MSAL XD-2 X-ray diffractometer. A Zetasizer Nano-ZS particle analyzer (Malvern Instruments Limited) (Malvin City, UK) was used. The chemical composition was determined by Fourier transform infrared spectroscopy (FT-IR, Equinox 55, Bruker, Billerica, MA, USA) and UV-vis-NIR spectrophotometry.

\section{Determination of the NS-grafted RGD peptide content}

The $\mathrm{Bi}_{2} \mathrm{Se}_{3}$-CS-RGD NSs were removed from the reaction solution by centrifugation. The supernatant was collected, and the residual peptides were determined using a BCA assay kit. The conjugated content of RGD peptide $\left(\mu \mathrm{g} \mathrm{mg}^{-1} \mathrm{NSs}\right)$ was determined by comparing the difference with the amount added.

\section{Cell culture and in vitro cytotoxicity test}

The human cervical carcinoma cell line HeLa, Siha, Caski and human melanoma A375 cells were obtained from the American Type Culture Collection (ATCC, Manassas, VA, USA), and Etc1/E6E7 human normal cervical endothelial cells were obtained from the Sunzhou BeNa Culture Collection. The HeLa, Siha, Caski and A375 cells were grown in DMEM, and the Etc1/E6E7 cells were cultured in MEM/NEAA medium supplemented with fetal bovine serum (10\%), 100 units per $\mathrm{ml}$ of penicillin, and 50 units per $\mathrm{ml}$ of streptomycin at $37^{\circ} \mathrm{C}$ in a humidified incubator under $5 \% \mathrm{CO}_{2}$. The cell viability $\left(2 \times 10^{4}\right.$ cells per $\left.\mathrm{ml}\right)$ after treatment with different concentrations of $\mathrm{Bi}_{2} \mathrm{Se}_{3} \mathrm{NSs}, \mathrm{Bi}_{2} \mathrm{Se}_{3}$-CS NSs, $\mathrm{Bi}_{2} \mathrm{Se}_{3}$-CS-RGD NSs and X-ray for $72 \mathrm{~h}$ was determined using an MTT assay. ${ }^{44}$

\section{Clonogenic assay}

The HeLa cells were seeded on six-well plates at 2000 cells per $\mathrm{ml}(2 \mathrm{ml})$ and allowed to attach for $24 \mathrm{~h}$. After incubation for $6 \mathrm{~h}$ with different concentrations of the $\mathrm{Bi}_{2} \mathrm{Se}_{3}$-CS-RGD NSs, the cells were exposed to different X-ray dosages and incubated at $37^{\circ} \mathrm{C}$ for 7 days. The cells were fixed with $4.0 \%$ paraformaldehyde ( $\mathrm{vol} / \mathrm{vol}$ ) for $10 \mathrm{~min}$ and stained with $0.5 \%$ crystal violet (wt/vol) for $20 \mathrm{~min}$. The survival fraction of the clones was used to evaluate the effects of different treatments.

\section{Cellular uptake and intracellular trafficking of NSs}

The in vitro cellular uptake and localization of the $\mathrm{Bi}_{2} \mathrm{Se}_{3}$-CS-RGD NSs were determined by using coumarin-6-loaded $\mathrm{Bi}_{2} \mathrm{Se}_{3}$-CS-RGD NSs. Solution of $5 \mathrm{mg} \mathrm{ml}^{-1}$ coumarin- 6 and CS were refluxed with ethanol. The products were purified by gel elution to remove unreacted coumarin- 6 , and the $\mathrm{Bi}_{2} \mathrm{Se}_{3} \mathrm{NS}$ solution was added to the CS-conjugated coumarin- 6 under constant stirring for $24 \mathrm{~h}$ in the dark to form the coumarin-6-loaded $\mathrm{Bi}_{2} \mathrm{Se}_{3}$-CS NSs. For RGD conjugation, the RGD was activated with EDC, NHS was added dropwise to the coumarin-6-loaded $\mathrm{Bi}_{2} \mathrm{Se}_{3}$-CS NSs, and the solution was stirred for $24 \mathrm{~h}$ at room temperature. After the reaction, the mixture was dialyzed against Milli-Q water for $24 \mathrm{~h}$, and the coumarin-6-loaded $\mathrm{Bi}_{2} \mathrm{Se}_{3}$-CS-RGD NSs were obtained.

$\mathrm{HeLa}$ and Etc1/E6E7 cells were seeded on six-well plates at a density of $2 \times 10^{5}$ cells per $\mathrm{ml}(2 \mathrm{ml})$ and incubated for $24 \mathrm{~h}$. The medium in each well was replaced with non-phenol red DMEM. After $2 \mathrm{~h}$, the cells were incubated with $160 \mu \mathrm{g} \mathrm{ml}^{-1}$ coumarin-6-loaded $\mathrm{Bi}_{2} \mathrm{Se}_{3}$-CS-RGD NSs for various durations at $37^{\circ} \mathrm{C}$ in a $\mathrm{CO}_{2}$ incubator. A total of $100 \mu \mathrm{l}$ of the medium was removed from the 96-well plates. The concentration was measured using the standardcurve method based on the specific absorbance of coumarin- 6 with the excitation and emission wavelengths set at 430 and $485 \mathrm{~nm}$, respectively, in the same medium. The cellular uptake efficiency was expressed as the percentage of $\mathrm{Bi}_{2} \mathrm{Se}_{3}$-CS-RGD NSs adsorbed to the amount added.

The lysosomal marker Lyso-tracker was used to trace the intracellular localization of coumarin-6-loaded $\mathrm{Bi}_{2} \mathrm{Se}_{3}$-CS-RGD NSs in the HeLa cells. The HeLa cells were incubated on 2-cm cell culture dishes with $80 \mathrm{~nm}$ Lyso-tracker for $2 \mathrm{~h}$ and $1 \mu \mathrm{g} \mathrm{ml}^{-1} \mathrm{H} 33342$ for $15 \mathrm{~min}$. After rinsing with phosphatebuffered saline (PBS) three times, the cells were incubated with $160 \mu \mathrm{g} \mathrm{ml}^{-1}$ coumarin-6-loaded $\mathrm{Bi}_{2} \mathrm{Se}_{3}$-CS-RGD NSs for various durations and observed by fluorescence microscopy (EVOSFL auto, Life Technologies, $20 \times$, Beijing, China).

\section{RGD competition assay}

The $\mathrm{Bi}_{2} \mathrm{Se}_{3}$-CS-RGD NSs and excess RGD competed for binding integrin on HeLa cells. The HeLa cells $\left(8 \times 10^{4}\right.$ cells ml $\left.^{-1}\right)$ were cultivated on 96 -well plates and incubated for $24 \mathrm{~h}$. Different concentrations of RGD $\left(0-0.5 \mathrm{mg} \mathrm{ml}^{-1}\right)$ were treated for $2 \mathrm{~h}$ at $37^{\circ} \mathrm{C}$ in a $\mathrm{CO}_{2}$ incubator and then incubated with $160 \mu \mathrm{g} \mathrm{ml}^{-1}$ coumarin-6-loaded $\mathrm{Bi}_{2} \mathrm{Se}_{3}$-CS-RGD NSs for $6 \mathrm{~h}$. The cells were rinsed with PBS three times and lysed. A fluorescence microplate reader (SpectraMax M5, Silicon Valley, Sunnyvale, CA, USA) with excitation and emission wavelengths of 430 and $485 \mathrm{~nm}$, respectively, was used to measure the internalized $\mathrm{Bi}_{2} \mathrm{Se}_{3}-$ CS-RGD NSs. The HeLa cells $\left(2 \times 10^{4}\right.$ cells per $\left.\mathrm{ml}\right)$ were incubated with different concentrations of RGD and $160 \mu \mathrm{g} \mathrm{ml}^{-1} \mathrm{Bi}_{2} \mathrm{Se}_{3}$-CS-RGD NSs for different durations and then exposed to X-ray (8Gy). After $24 \mathrm{~h}$, the cell viability was determined using an MTT assay.

\section{Flow cytometric analysis of the cell cycle distribution}

The effects of the $\mathrm{Bi}_{2} \mathrm{Se}_{3}$-CS-RGD NSs and X-ray irradiation on the cell cycle distribution were determined by flow cytometric analysis. The DNA histogram represents the percentages of cells in the G0/G1, S and G2/M phases, and the hypodiploid DNA content in the apoptotic cells was quantified by analyzing the sub-G1 peak. ${ }^{26}$

\section{Caspase activity assay}

The activation of caspases was examined by measuring the fluorescence intensity with specific caspase- $3,-8$ and -9 substrates. Briefly, HeLa cells with $40 \mu \mathrm{g} \mathrm{ml}^{-1} \mathrm{Bi}_{2} \mathrm{Se}_{3}$-CS-RGD NSs and X-ray (8 Gy) treatment for $72 \mathrm{~h}$ were incubated with lysis buffer (Beyotime) to obtain the total cellular proteins. The protein concentrations were determined using a BCA assay. A total of $100 \mu \mathrm{g}$ of the cytosolic protein and caspase substrates (caspase-3, -8 and -9) were added to the 96 -well plates at $37^{\circ} \mathrm{C}$ for $2 \mathrm{~h}$. The caspase activity was examined using a fluorescence microplate reader with excitation and emission wavelengths of 380 and $460 \mathrm{~nm}$, respectively. The fluorescence intensity was monitored to evaluate the caspase activity. ${ }^{45}$

\section{Change of mitochondrial morphology}

The HeLa cells were cultured on $2 \mathrm{~cm}$ glass-bottom dishes for $24 \mathrm{~h}$. They were treated with the $\mathrm{Bi}_{2} \mathrm{Se}_{3}$-CS-RGD NSs $\left(40 \mu \mathrm{g} \mathrm{ml}^{-1}\right)$ for $6 \mathrm{~h}$ and then irradiated with X-ray (8 Gy). After incubation for $12 \mathrm{~h}$, the cell monolayer was rinsed with ice-cold PBS 3 times. The cell mitochondria and nuclei were stained with $100 \mathrm{~nm}$ Mito-tracker for $2 \mathrm{~h}$ and $1 \mu \mathrm{g} \mathrm{ml}^{-1} \mathrm{H} 33342$ for $15 \mathrm{~min}$. Changes in the mitochondrial morphology were observed by fluorescence microscopy (EVOSFL auto, Life Technologies, $100 \times$ ).

\section{Examination of the TrxR activity}

A Thioredoxin Reductase Assay Kit (Cayman, Ann Arbor, MI, USA) was used to determine the inhibition of TrxR in the HeLa cells after different treatments. In this assay, TrxR catalyzes the reduction of 5,5-dithiobis (2-nitrobenzoic) acid (DTNB) with NADPH to 5-thio-2-nitrobenzoic acid $\left(\mathrm{TNB}^{2-}\right)$, generating a strong yellow color. Briefly, $60 \mu \mathrm{g}$ of cytosolic protein was added to 96-well plates and incubated with NADPH and DTNB for $30 \mathrm{~min}$. The reaction was monitored at $410 \mathrm{~nm}$ using a microplate reader (MD VERSA max, Silicon Valley), and the TrxR activity was expressed as \% of the control.

\section{Detection of singlet oxygen in vitro}

The traditional chemical probe of 1,3-diphenylisobenzofuran (DPBF) was used to identify the generation of ${ }^{1} \mathrm{O}_{2}$, which could react with ${ }^{1} \mathrm{O}_{2}$ and cause a decrease in the absorption intensity of the DPBF band centered at $410 \mathrm{~nm}$. One milliliter of ethanol solution with DPBF (2 mM) was mixed with $1 \mathrm{ml}$ of $\mathrm{Bi}_{2} \mathrm{Se}_{3}-$ CS-RGD NSs at a specified concentration in the dark for $2 \mathrm{~h}$ to reach the 

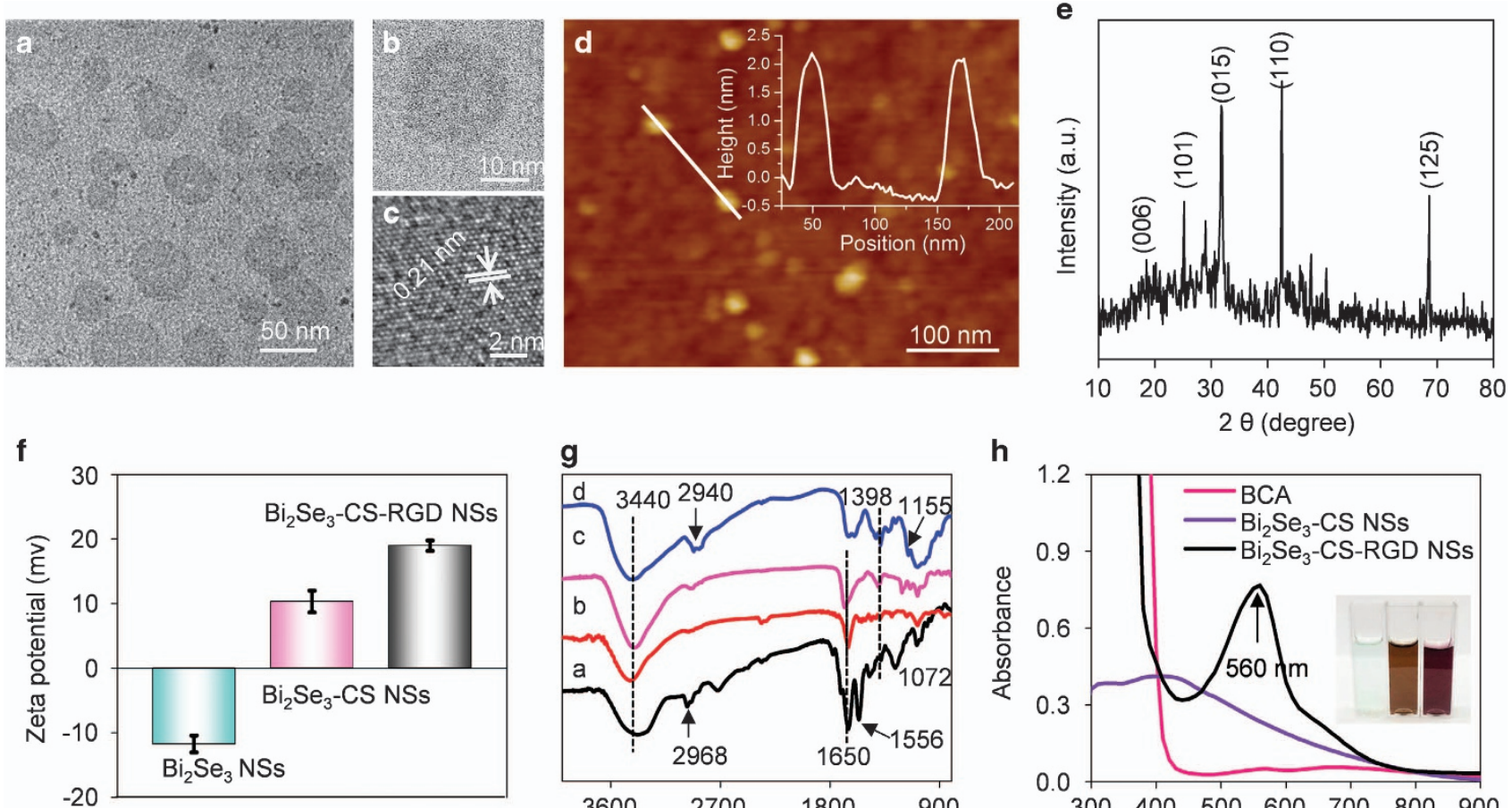

g

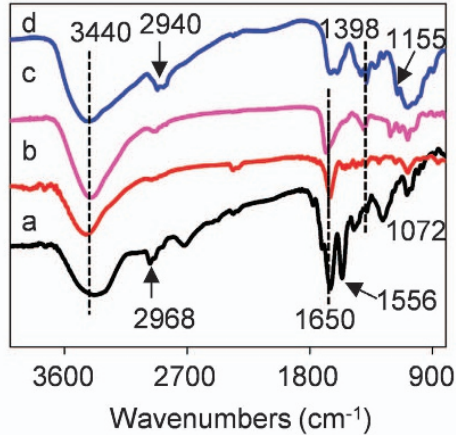

h



Figure 1 Characterizations of $\mathrm{Bi}_{2} \mathrm{Se}_{3}-\mathrm{CS}-\mathrm{RGD}$ NSs. (a) TEM image, (b) Magnified TEM image, (c) HR-TEM image, (d) AFM image, (e) XRD spectra of the $\mathrm{Bi}_{2} \mathrm{Se}_{3}-\mathrm{CS}-\mathrm{RGD}$ NSs. (f) Zeta potential of $\mathrm{Bi}_{2} \mathrm{Se}_{3}, \mathrm{Bi}_{2} \mathrm{Se}_{3}-\mathrm{CS}$ and $\mathrm{Bi}_{2} \mathrm{Se}_{3}-\mathrm{CS}-\mathrm{RGD} \mathrm{NSs}$. (g) FT-IR spectra of (a) Bi $2 \mathrm{Se} \mathrm{e}_{3}-\mathrm{CS}-\mathrm{RGD} \mathrm{NSs}$, (b) CS-RGD, (c) RGD and (d) CS. (h) UV-vis-NIR spectra showing the changes of $560 \mathrm{~nm}$ absorbance and solution color of BCA buffer after reaction with Bi $\mathrm{B}_{2}$-CS-RGD NSs by using $\mathrm{Bi}_{2} \mathrm{Se}_{3}-\mathrm{CS} \mathrm{NSs}$ as the control.

adsorption/desorption equilibrium prior to the testing. Then, the mixed solution was exposed to different dosages of X-ray, and the absorbance at $410 \mathrm{~nm}$ was monitored using a UV-vis spectrophotometer. In the cell model, the HeLa cells $\left(4 \times 10^{4}\right.$ cells per ml) were treated with the $\mathrm{Bi}_{2} \mathrm{Se}_{3}-\mathrm{CS}-\mathrm{RGD} \mathrm{NSs}$ $\left(40 \mu \mathrm{g} \mathrm{ml}^{-1}\right)$ for $4 \sim 5 \mathrm{~h}$ followed by incubation with DPBF $(0.1 \mathrm{~mm}$ final concentration) for $2 \mathrm{~h}$ and irradiation with X-ray ( $8 \mathrm{~Gy}$ ). The generation of ${ }^{1} \mathrm{O}_{2}$ was measured by detecting the absorbance of DPBF at $410 \mathrm{~nm}$ every $5 \mathrm{~min}$.

\section{Determination of intracellular reactive oxygen species (ROS) generation}

The effects of the $\mathrm{Bi}_{2} \mathrm{Se}_{3}$-CS-RGD NSs and radiation on intracellular superoxide generation in the HeLa cells were examined using the dihydroethidium (DHE) fluorescence probe. Briefly, the HeLa cells $\left(2 \times 10^{5}\right.$ cells per $\left.\mathrm{ml}\right)$ were treated with the $\mathrm{Bi}_{2} \mathrm{Se}_{3}$-CS-RGD NSs for $6 \mathrm{~h}$. Then, the cells were treated with X-ray (8 Gy) and incubated with DHE at a final concentration of $10 \mu \mathrm{M}$ at $37^{\circ} \mathrm{C}$ for $30 \mathrm{~min}$. The intracellular reactive oxygen species (ROS) level was measured as the fluorescence intensity of DHE (excitation and emission wavelengths of 300 and $600 \mathrm{~nm}$, respectively). Fluorescence images were acquired from the HeLa cells to examine whether the combined radiotherapy induced variations in ROS. The cell-free model was the same as that described above except that the cultured HeLa cells were replaced by PBS.

\section{ABTS radical scavenging activity}

The antioxidant activity was assessed using an ABTS assay according to the requirement of the Total Antioxidant Capacity Assay Kit. The $\mathrm{ABTS}^{++}$radical was formed by the same volume of ABTS and oxidant solution after incubation at room temperature in darkness for $12 \sim 18 \mathrm{~h}$. The radical was diluted with PBS $(\mathrm{pH}=7.4)$ to obtain an absorbance value of $0.700 \pm 0.0200$ at $734 \mathrm{~nm}$. Under dark conditions, $190 \mu \mathrm{l}$ of the $\mathrm{ABTS}^{*+}$ radical solution was added to $10 \mu \mathrm{l}$ of the $\mathrm{Bi}_{2} \mathrm{Se}_{3} \mathrm{NSs}, \mathrm{Bi}_{2} \mathrm{Se}_{3}$-CS NSs and $\mathrm{Bi}_{2} \mathrm{Se}_{3}$-CS-RGD NSs at different concentrations, and the absorbance at $734 \mathrm{~nm}$ was measured using a microplate reader.

\section{Western blot analysis}

The effects on the expression levels of proteins associated with different signaling pathways were determined by Western blot analysis. ${ }^{46}$

\section{Tumor model}

Female Balb/c nude mice (3-4 weeks old and weighing 14-15 g) were purchased from Beijing HFK Bioscience (Beijing, China) and used under protocols approved by the Jinan University Laboratory Animal Center. The animals acclimated to the environment for 10 days before treatment. HeLa cells $\left(1 \times 10^{7}\right.$ cells $\left.\mathrm{ml}^{-1}\right)$ suspended in $100 \mu \mathrm{l}$ of PBS were subcutaneously injected into the back of each mouse to develop the tumor. All the procedures were in compliance with the animal ethics committee guidelines.

\section{In vivo photoacoustic imaging}

The Balb/c nude mice bearing HeLa tumors $(7-8 \mathrm{~mm})$ were intravenously and intratumorally injected with the $\mathrm{Bi}_{2} \mathrm{Se}_{3} \mathrm{NSs}\left(1 \mathrm{mg} \mathrm{ml}^{-1}, 0.1 \mathrm{ml}\right)$ and $\mathrm{Bi}_{2} \mathrm{Se}_{3}$-CSRGD NSs $\left(1 \mathrm{mg} \mathrm{ml}^{-1}, 0.1 \mathrm{ml}\right)$, respectively. Photoacoustic imaging was performed using a photoacoustic computed tomography scanner (Endra Nexus 128, Ann Arbor, MI, USA), and $808 \mathrm{~nm}$ was selected as the laser wavelength with an average of 30 pulses. Anesthesia was administered with pentobarbital $(2 \%, \mathrm{wt} / \mathrm{vol}, 30 \mu \mathrm{l})$, and a water heating system maintained the water temperature at $37.5^{\circ} \mathrm{C}$ to keep the mice comfortable. Photoacoustic images were obtained at different time intervals. ${ }^{47}$

\section{Biodistribution}

The $\mathrm{Bi}_{2} \mathrm{Se}_{3}$-CS-RGD NSs and $\mathrm{Bi}_{2} \mathrm{Se}_{3}$ NSs were injected into the Balb/c nude mice $\left(1 \mathrm{mg} \mathrm{ml}^{-1}, 0.1 \mathrm{ml}\right)$ intravenously and intratumorally, respectively. At 12, 24, 36 and $48 \mathrm{~h}$ post injection, the mice were killed, and the tissues were excised, weighed, and digested in $\mathrm{HNO}_{3}$ and $\mathrm{HClO}_{4}$ (3:1) for $180^{\circ} \mathrm{C}$. The homogenized tissue lysates were dried using heat, diluted with ultrapure water, and filtered. The Bi and Se contents were determined by inductively coupled plasma mass spectrometry. 

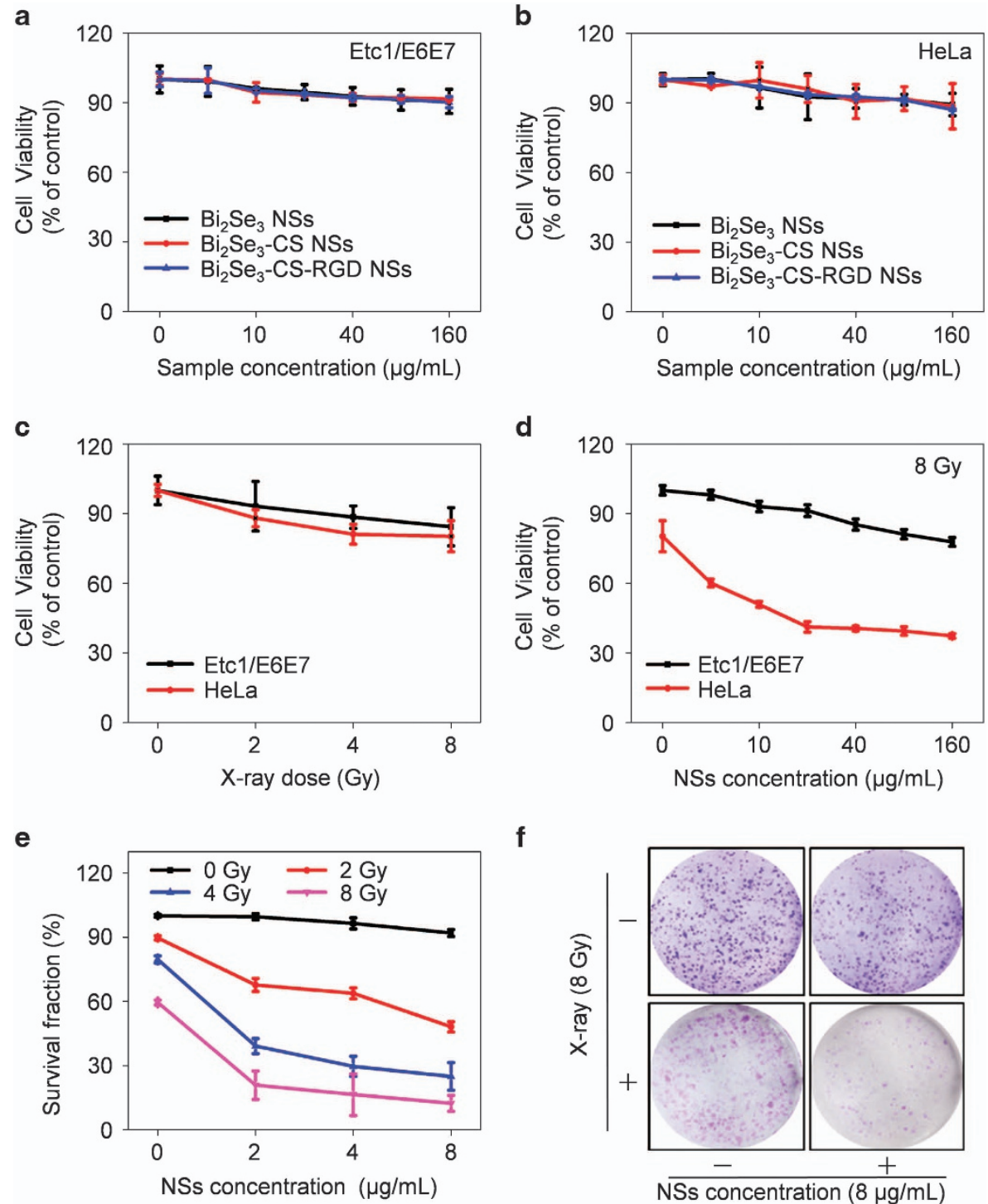

Figure $2 \mathrm{Bi}_{2} \mathrm{Se}_{3}-\mathrm{CS}-\mathrm{RGD}$ NSs sensitizes cancer cells to X-ray. The Etc1/E6E7 normal cells (a) and HeLa cancer cells (b) were treated with different concentrations of the three NSs for $72 \mathrm{~h}$. (c) Etc1/E6E7 and HeLa cells were treated with different doses of X-ray (0-8 Gy) then incubated for another $72 \mathrm{~h}$. (d) Etc1/E6E7 and HeLa cells were treated with different concentrations of $\mathrm{Bi}_{2} \mathrm{Se}_{3}$-CS-RGD NSs $\left(0-160 \mu \mathrm{g} \mathrm{ml}{ }^{-1}\right.$ ) for $6 \mathrm{~h}$ and exposed with X-ray (8 Gy), then cultured for another $72 \mathrm{~h}$. The above cell viabilities were examined by MTT assay. (e) Clonogenic assay of HeLa cells under the co-treatment of $\mathrm{Bi}_{2} \mathrm{Se}_{3}-\mathrm{CS}_{-}$ RGD NSs with different concentrations and X-ray radiation with different doses. (f) Colony formation of HeLa cells under the cotreatment of $\mathrm{Bi}_{2} \mathrm{Se}_{3}-\mathrm{CS}-\mathrm{RGD}$ NSs $\left(8 \mu \mathrm{g} \mathrm{ml}^{-1}\right)$ and radiation ( $\left.8 \mathrm{~Gy}\right)$. Values expressed are means \pm s.d. of triplicates.

\section{In vivo assessment of the radiation therapy effect}

When the tumor grew to $5-6 \mathrm{~mm}$ in diameter, the mice were randomly divided into eight groups (three mice per group): G1: saline, as a control group; G2: $\mathrm{X}$-ray; G3: $\mathrm{Bi}_{2} \mathrm{Se}_{3}-\mathrm{CS}-\mathrm{RGD}$ NSs (intravenous); $\mathrm{G} 4: \mathrm{Bi}_{2} \mathrm{Se}_{3}-\mathrm{CS}-\mathrm{RGD}$ NSs (intratumoral); G5: $\mathrm{Bi}_{2} \mathrm{Se}_{3}$ NSs (intravenous) + X-ray; G6: $\mathrm{Bi}_{2} \mathrm{Se}_{3}$ NSs (intratumoral) + X-ray; G7: $\mathrm{Bi}_{2} \mathrm{Se}_{3}$-CS-RGD NSs (intravenous) + X-ray; and G8: $\mathrm{Bi}_{2} \mathrm{Se}_{3}$-CS-RGD NSs (intratumoral) + X-ray. A PBS solution of $\mathrm{Bi}_{2} \mathrm{Se}_{3} \mathrm{NSs}$ $\left(1 \mathrm{mg} \mathrm{ml}^{-1}, 0.1 \mathrm{ml}\right)$ was intravenously injected into each tumor in the G5 mice for $6-8 \mathrm{~h}$ and intratumorally injected into each tumor of the G6 mice for $0.5 \mathrm{~h}$. A PBS solution of $\mathrm{Bi}_{2} \mathrm{Se}_{3}$-CS-RGD NSs $\left(1 \mathrm{mg} \mathrm{ml}^{-1}, 0.1 \mathrm{ml}\right)$ was intravenously injected into each tumor of the G3 and G7 mice for 6-8 h and intratumorally injected into each tumor of the G4 and G8 mice for $0.5 \mathrm{~h}$. A total of $100 \mu \mathrm{l}$ of saline was injected into each tumor in G1. After the injections, the G2, G5, G6, G7 and G8 mice were anesthetized using pentobarbital and underwent X-ray irradiation (4 Gy and $6 \mathrm{MeV}$ energy, $5 \mathrm{~cm}$ penetration, $100 \mathrm{MU}$ ) of the tumor $100 \mathrm{~cm}$ from the source using a $2-\mathrm{cm}$-thick lead plate with holes of appropriate size for protection. After one day, the process was repeated nine times to achieve $40 \mathrm{~Gy}$ of exposure. During the treatment, the body weight of the mice and size of the tumors were measured daily for 21 days, and the tumor volume was calculated as the width ${ }^{2} \times$ length $/ 2$.

\section{In vivo magnetic resonance $(\mathrm{MR})$ imaging}

After 21 days, the mice were anesthetized with $2 \%$ pentobarbital $(40 \mu \mathrm{l})$ and placed under magnetic resonance imaging (MRI) study conditions. Imaging analysis was performed using the Imaging software, and a quantification analysis of the MR signals was performed using the MR images. The $T_{2}$-weighted MR images were obtained using a $1.5 \mathrm{~T}$ Signa HDxt superconductor clinical MR system (GE medical, Milwaukee, WI, USA) using the following parameters: TR $2620 \mathrm{~ms}$; TE $82.3 \mathrm{~ms}$; slice thickness $2.0 \mathrm{~mm}$; slice spacing $0.2 \mathrm{~mm}$; matrix $256 \times 192$; and FOV $5 \mathrm{~cm} \times 5 \mathrm{~cm}$.

\section{Hematological and histological analyses}

After the experiments, blood samples $(\sim 1 \mathrm{ml})$ were collected from the eyes of the nude mice before sacrifice and centrifuged to obtain the serum $(\sim 500 \mu \mathrm{l})$, 
a
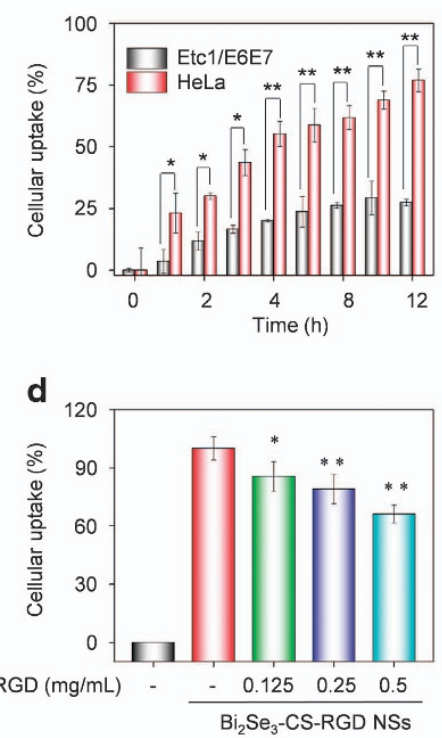

b

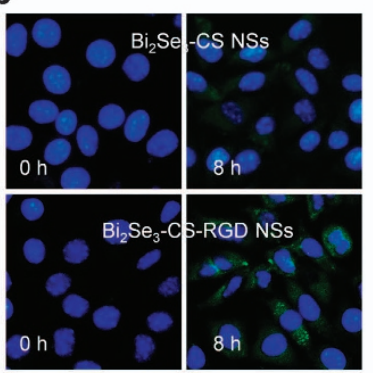

e

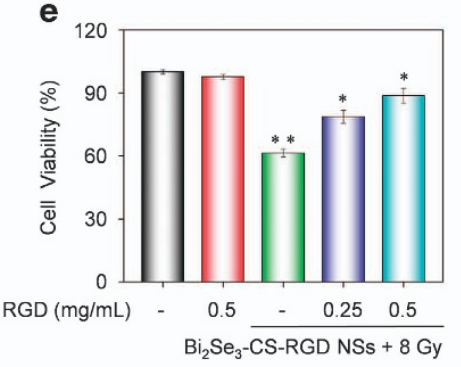

C

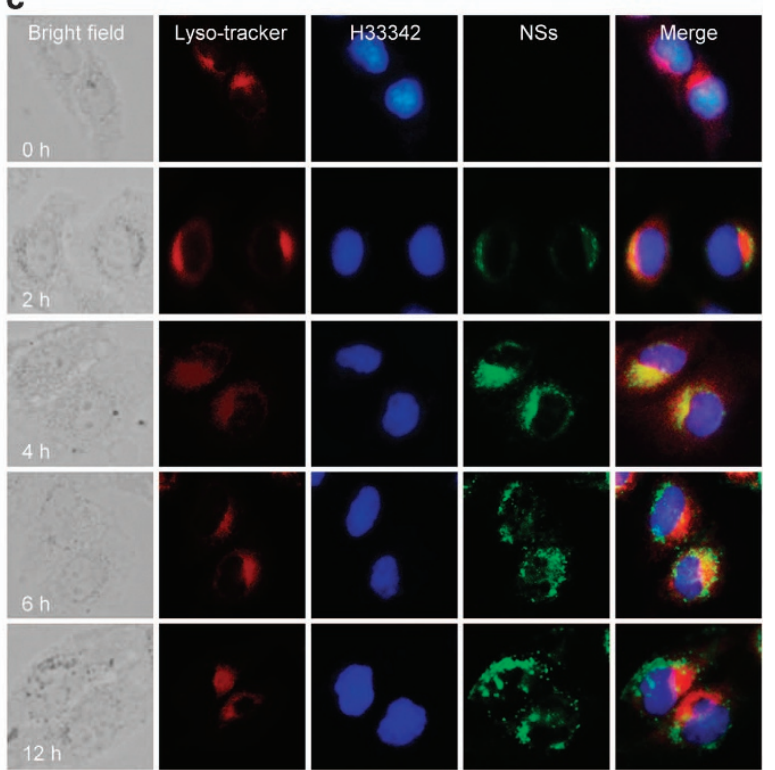

Figure 3 Cellular uptake and trafficking of $\mathrm{Bi}_{2} \mathrm{Se}_{3}-\mathrm{CS}-\mathrm{RGD}$ NSs. (a) Quantitative analysis of cellular uptake efficiency of coumarin-6-loaded $\mathrm{Bi}_{2} \mathrm{Se}_{3}-\mathrm{CS}-\mathrm{RGD}$ NSs in HeLa and Etc1/E6E7 cells after different time periods of incubation. (b) Fluorescence microscope images showing the internalization of coumarin-6loaded $\mathrm{Bi}_{2} \mathrm{Se}_{3}$-CS NSs and coumarin-6-loaded $\mathrm{Bi}_{2} \mathrm{Se}_{3}$-CS-RGD NSs with the same concentration of $160 \mu \mathrm{g} \mathrm{ml}{ }^{-1}$ in HeLa cells before and after incubation. (c) Intracellular trafficking of Hela cells, which were incubated with coumarin-6-loaded $\mathrm{Bi}_{2} \mathrm{Se}_{3}$-CS-RGD NSs $\left(160 \mu \mathrm{g} \mathrm{ml}{ }^{-1}\right)$ for different periods of time and stained with Lyso-tracker (red, lysosome) and Hoechst 33342 (blue, nucleus). Original magnification: $\times 20$. (d) Dose-dependent manner of RGD blocks the cellular uptake of coumarin-6-loaded $\mathrm{Bi}_{2} \mathrm{Se}_{3}-\mathrm{CS}-\mathrm{RGD}$ NSs. (e) Cell viability was examined by MTT assay. Values expressed were means \pm s.d. of triplicate. ${ }^{*} P<0.05$ vs control. ${ }^{* *} P<0.01$ vs control.

which was sent to the Blood Test Center of Guangzhou Overseas Chinese Hospital for blood panel analysis and blood chemistry assays. The tumor tissue and main organs (heart, liver, spleen, lung and kidney) were stripped and weighed. A paraffin section was made and stained with hematoxylin and eosin (H\&E) for further observation of the pathological changes caused by different treatments. The percentage of the relative tumor growth ratio was calculated as $\left(\mathrm{V}_{21}-\mathrm{V}_{0}\right)_{\mathrm{Gi}} /\left(\mathrm{V}_{21}-\mathrm{V}_{0}\right)_{\mathrm{G} 1}{ }^{\star} 100 \%$.

\section{Statistical analysis}

All the experiments were conducted in at least triplicate and repeated three times; the results are expressed as the mean \pm s.d. The differences between the control and experimental groups were analyzed by a two-tailed Student's $t$-test. Differences with $P<0.05\left({ }^{*}\right)$ or $P<0.01\left({ }^{*}\right)$ were considered statistically significant.

\section{RESULTS AND DISCUSSION}

Targeted design and characterization of $\mathrm{Bi}_{2} \mathrm{Se}_{3}-\mathrm{CS}-\mathrm{RGD}$ NSs As shown in the transmission electron microscopy images in Figures $1 \mathrm{a}$ and $\mathrm{b}$, the $\mathrm{Bi}_{2} \mathrm{Se}_{3}$-CS-RGD NSs have a sheet-like morphology with an average diameter of $\sim 30 \mathrm{~nm}$. The high-resolution transmission electron microscopy image presented in Figure 1c shows hexagonal lattice fringes with $0.21 \mathrm{~nm}$ spacing corresponding to the (110) plane of the $\mathrm{Bi}_{2} \mathrm{Se}_{3}$ crystal. ${ }^{48}$ The AFM image in Figure 1d shows heights of 2.18 and $2.07 \mathrm{~nm}$, corresponding to a stack of $\sim 2$ quantum layers (QLs) of $\mathrm{Bi}_{2} \mathrm{Se}_{3}$. The NSs are further characterized by powder $\mathrm{XRD}$. As shown in Figure 1e, all the peaks can be indexed to the rhombohedral phase of $\mathrm{Bi}_{2} \mathrm{Se}_{3} \cdot{ }^{48}$ Compared to the bare $\mathrm{Bi}_{2} \mathrm{Se}_{3} \mathrm{NSs}$ (see Supplementary Figure S1A, B) surface modification does not change the morphology and structure of the $\mathrm{Bi}_{2} \mathrm{Se}_{3} \mathrm{NSs}$.

The zeta potentials shown in Figure if provide direct evidence of the modification of the $\mathrm{Bi}_{2} \mathrm{Se}_{3} \mathrm{NSs}$. The zeta potential of the original $\mathrm{Bi}_{2} \mathrm{Se}_{3} \mathrm{NSs}$ is $-11.7 \mathrm{mV}$ because PVP is used in the synthesis. The zeta potential of the $\mathrm{Bi}_{2} \mathrm{Se}_{3}-\mathrm{CS} \mathrm{NSs}$ is $+10.3 \mathrm{mV}$ after modification with positively charged CS and $+18.9 \mathrm{mV}$ after conjugation with RGD. Successful surface modification is confirmed by the gradual increase in the hydrodynamic particle size of the NSs (Supplementary Figure S1C). The chemical structure of the $\mathrm{Bi}_{2} \mathrm{Se}_{3}-\mathrm{CS}-\mathrm{RGD} \mathrm{NSs}$ is determined using Fourier transform infrared spectroscopy. Figure $1 \mathrm{~g}$ shows the characteristic absorption of the hydroxyl group $(-\mathrm{O}-\mathrm{H})$ at $3440 \mathrm{~cm}^{-1}$. The peak in the CS spectrum at $2940 \mathrm{~cm}^{-1}$ shifts to $2968 \mathrm{~cm}^{-1}$ in the $\mathrm{Bi}_{2} \mathrm{Se}_{3}$-CS-RGD NS spectrum due to a weak interaction between the amino group and Se atoms on the surface of the $\mathrm{Bi}_{2} \mathrm{Se}_{3} \mathrm{NSs}$. The peaks at 1398, 1155 and $1072 \mathrm{~cm}^{-1}$ correspond to stretching of $\mathrm{C}-\mathrm{H}, \mathrm{C}-\mathrm{O}-\mathrm{C}$, and $\mathrm{C}-\mathrm{O}-\mathrm{H}$, respectively, characteristic of CS. ${ }^{49}$ The two amide bands I and II at 1650 and $1556 \mathrm{~cm}^{-1}$, respectively, in the spectrum of the $\mathrm{Bi}_{2} \mathrm{Se}_{3}$-CS-RGD NSs confirm the formation of -CO-NH- between RGD and CS. The Fourier transform infrared spectroscopy results corroborate the surface conjugation of $\mathrm{CS}$ and RGD onto the $\mathrm{Bi}_{2} \mathrm{Se}_{3}$ surface.

The presence of RGD peptides is verified by a protein staining BCA assay and UV-vis-NIR spectroscopy. The absorption spectrum in Figure $1 \mathrm{~h}$ shows higher absorbance at $560 \mathrm{~nm}$ due to the presence of proteins in the NPs, which is confirmed by the change in the particle color (inset photos). The coupling amount of RGD peptide is $20.54 \mu \mathrm{g} \mathrm{mg}^{-1}$. In this nanosystem, the positive charge from the amine groups of CS facilitates internalization in the tumor cells through endocytosis. Moreover, RGD peptide surface decoration enhances the recognition of the NSs by the integrin that is overexpressed in the cancer cell membrane, thus increasing the selectivity between the cancer and normal cells.

The stability of the $\mathrm{Bi}_{2} \mathrm{Se}_{3}$-CS-RGD NSs is examined. It has been observed that naked $\mathrm{Bi}_{2} \mathrm{Se}_{3}$ NSs are oxidized extensively in PBS buffer solution $(\mathrm{pH}=7.4)$ after exposure to ambient conditions (room temperature) for one month, and the color changes from black to brown before precipitation of red amorphous Se sediment. ${ }^{41}$ 
a

NSs concentration $(\mu \mathrm{g} / \mathrm{mL})$

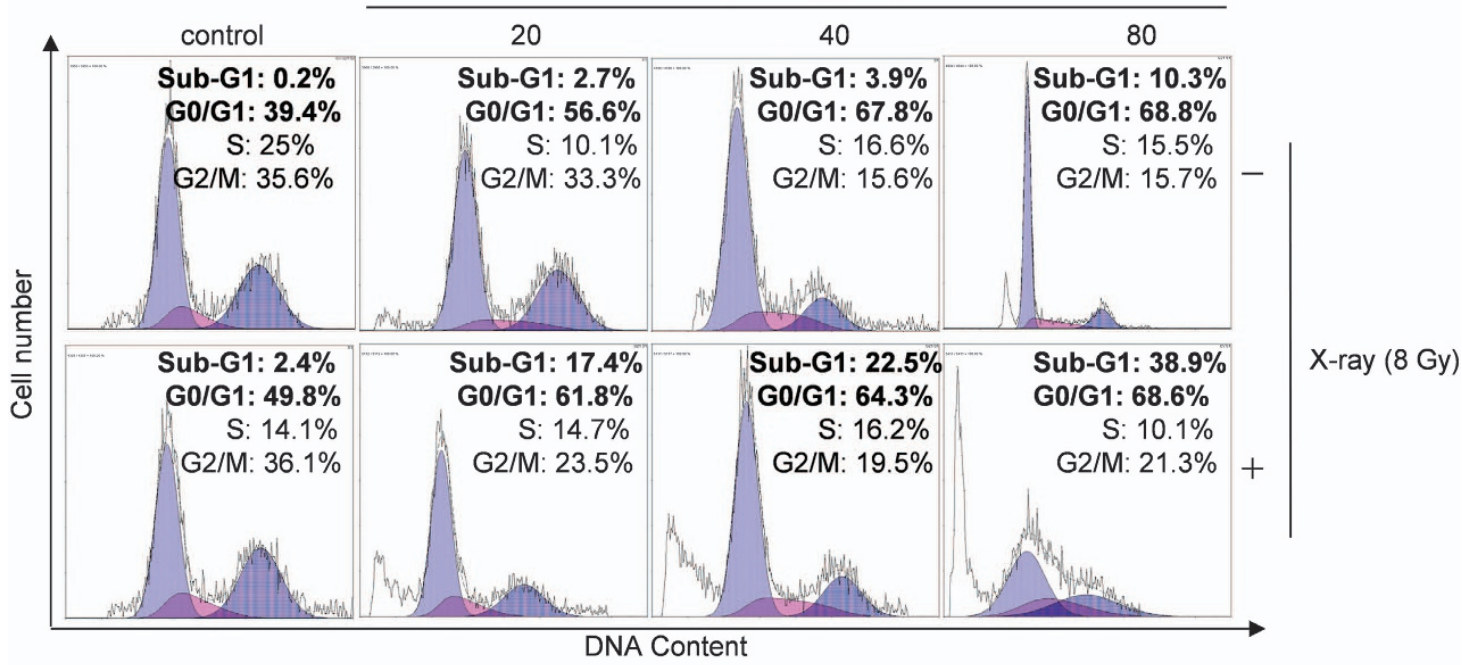

b

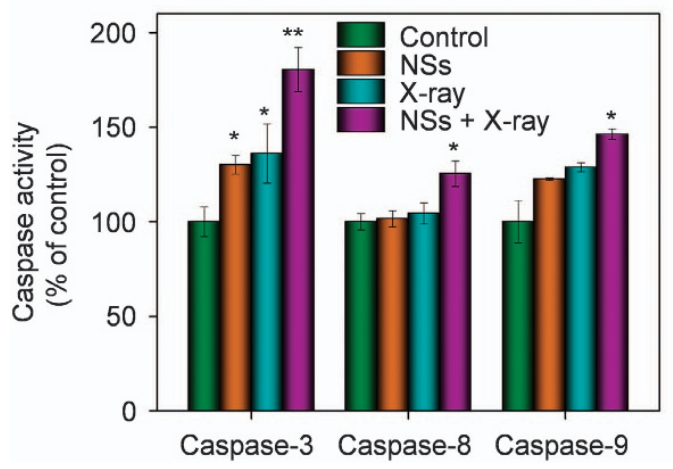

C NSs concentration $(40 \mu \mathrm{g} / \mathrm{mL})$

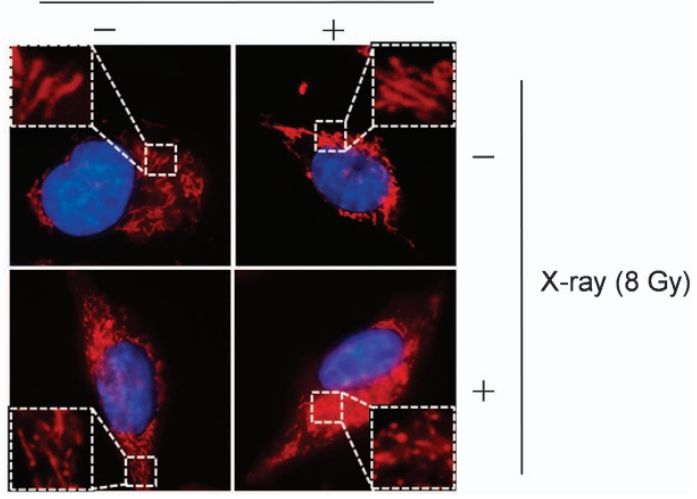

Figure 4 Action mechanisms for the NSs-enhanced X-ray radiotherapy. (a) Flow cytometric analysis of $\mathrm{HeLa}$ cells after being treated with or without $\mathrm{Bi}_{2} \mathrm{Se}_{3}{ }^{-}$ CS-RGD NSs and X-ray ( $8 \mathrm{~Gy}$ ). (b) Quantitative analysis of caspase activation triggered by $\mathrm{Bi}_{2} \mathrm{Se}_{3}$-CS-RGD NSs and X-ray. HeLa cells were treated with $\mathrm{Bi}_{2} \mathrm{Se}_{3}$-CS-RGD NSs $\left(40 \mu \mathrm{g} \mathrm{ml} \mathrm{I}^{-1}\right.$ ) and X-ray ( $\left.8 \mathrm{~Gy}\right)$ for $72 \mathrm{~h}$. Caspase activities were determined by synthetic fluorogenic substrate. Values expressed were means \pm s.d. of triplicates. ${ }^{*} P<0.05$ vs. control. ${ }^{* *} P<0.01$ vs. control. (c) The morphological change of mitochondria in cells after treatments with or without $\mathrm{Bi}_{2} \mathrm{Se}_{3}-\mathrm{CS}-\mathrm{RGD}$ NSs and X-ray (8 Gy). The cells were incubated for $12 \mathrm{~h}$ then staining with Hoechst 33342 (blue) and Mito-tracker (red), and then observed under a fluorescent microscope. Original magnification: $\times 100$.

In comparison, Supplementary Figure S2 (Supplementary) shows that the $\mathrm{Bi}_{2} \mathrm{Se}_{3}$-CS-RGD NSs have excellent stability in PBS for more than 30 days at $4{ }^{\circ} \mathrm{C}$ and in DMEM containing $10 \%$ FBS, simulating physiological conditions, for $72 \mathrm{~h}$.

The stability of the $\mathrm{Bi}_{2} \mathrm{Se}_{3}$-CS-RGD NSs under X-ray irradiation is assessed because it influences the efficiency in radiosensitization applications. ${ }^{50}$ As shown in Supplementary Figure S3 (Supplementary), the morphology and crystal structure of the $\mathrm{Bi}_{2} \mathrm{Se}_{3}$-CS-RGD NSs are preserved after X-ray $(8 \mathrm{~Gy}, 6 \mathrm{MeV})$ irradiation for as long as 2 min due to the strong chemical bonds in the $\mathrm{Bi}_{2} \mathrm{Se}_{3}$-CS-RGD NSs (Se-Bi-Se-Bi-Se).

\section{Enhanced cancer radiotherapy}

Although radiation therapy is widely adopted in the treatment of cervical cancer, the clinical success rate is unsatisfactory. This result is partly associated with the resistance to radiotherapy caused by hypoxic cells in the tumor microenvironment. In this study, the $\mathrm{Bi}_{2} \mathrm{Se}_{3}$-CSRGD NSs exhibit a radiotherapy-enhancing effect of X-ray irradiation on cervical cancer. The MTT assay shows that after treatment for $72 \mathrm{~h}$, the $\mathrm{Bi}_{2} \mathrm{Se}_{3} \mathrm{NSs}, \mathrm{Bi}_{2} \mathrm{Se}_{3}$-CS NSs, $\mathrm{Bi}_{2} \mathrm{Se}_{3}$-CS-RGD NSs (Figures $2 \mathrm{a}$ and $\mathrm{b}$ ) and $\mathrm{X}$-ray radiation (Figure $2 \mathrm{c}$ ) alone show no significant inhibition of
HeLa and Etc1/E6E7 cells. It has been reported that high-dose irradiation increases the cytotoxic effects on tumors. ${ }^{51}$ In this study, exposure to $8 \mathrm{~Gy}$ X-ray only inhibits HeLa cell growth by $20 \%$ (Figure 2c), thus demonstrating the radiation resistance of HeLa cells. By contrast, the combined treatment with the $\mathrm{Bi}_{2} \mathrm{Se}_{3}$-CS-RGD NSs and $\mathrm{X}$-ray radiation results in higher growth inhibition of HeLa cells in a dose-dependent manner (Figure 2d). The NSs and X-ray also show synergistic effects on other cell lines, including Siha and Caski human cervical carcinoma cells and A375 human melanoma cells (Supplementary Figure S4). The combination indexes (CIs) of the co-treatment are $0.41\left(8 \mathrm{~Gy}: 80 \mu \mathrm{g} \mathrm{ml}^{-1}\right)$ and $0.47\left(8 \mathrm{~Gy}: 40 \mu \mathrm{g} \mathrm{ml}^{-1}\right)$, as shown in Supplementary Figure S5 (Supplementary), confirming the synergistic effects of X-ray and the NSs. In comparison, the combined treatment shows no toxicity in the Etc1/E6E7 human normal cervical endothelial cells, confirming the good selectivity of the $\mathrm{Bi}_{2} \mathrm{Se}_{3}-\mathrm{CS}-\mathrm{RGD} \mathrm{NSs}$ as a radiosensitizer between cancer and normal cells.

The clonogenic assay is used to evaluate the anticancer effects of NSs and X-ray on the cell population by examining the inhibitory effects of the combined treatment on the colony formation of HeLa cells. As shown in Figure 2e, the survival fractions of HeLa cells treated 
a

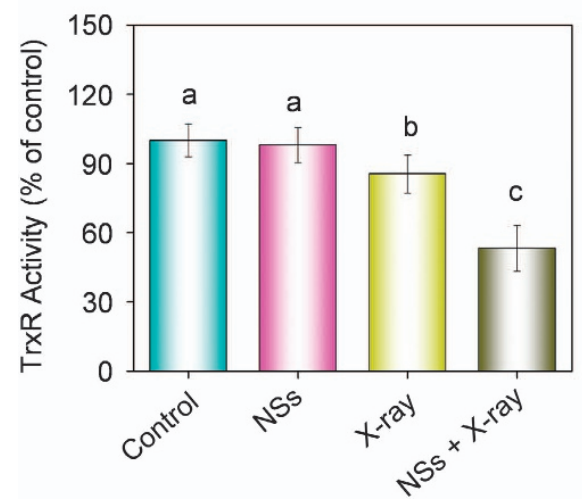

b

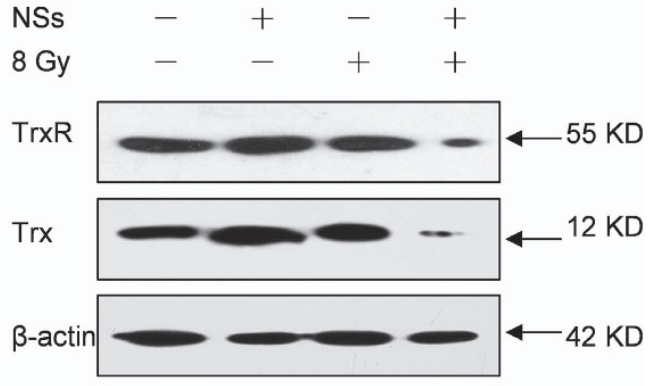

Figure $5 \mathrm{Bi}_{2} \mathrm{Se}_{3}$-CS-RGD NSs enhances radio-sensitivity of HeLa cells to X-ray by inhibition of TrxR activity. (a) The HeLa cells were pretreated $\mathrm{Bi}_{2} \mathrm{Se}_{3}-\mathrm{CS}$ RGD NSs $\left(40 \mu \mathrm{g} \mathrm{ml}^{-1}\right)$ for $6 \mathrm{~h}$, and then co-treated with or without X-ray (8 Gy), then the cells were cultured for another $72 \mathrm{~h}$. The inhibition of TrxR was measured using a Thioredoxin Reductase Assay Kit. Bars with different characters (a, b, and c) are statistically different at * $P<0.05$ level. Values expressed are means \pm s.d. of triplicates. (b) Western blot analysis of expression levels of TrxR and Trx in HeLa cells treated with $\mathrm{Bi}_{2} \mathrm{Se}_{3}-\mathrm{CS}-\mathrm{RGD} \mathrm{NSs}(40 \mu \mathrm{g}$ ml) and radiation for $72 \mathrm{~h}$.

with X-ray (2 Gy) and NSs $\left(8 \mu \mathrm{g} \mathrm{ml}^{-1}\right)$ alone are $89.7 \%$ and $91.9 \%$, respectively, and this fraction is reduced to $48.1 \%$ after the combined treatment. When the X-ray dose is increased, the survival fraction of the HeLa cells declines to $24.9 \%$ and $12.4 \%$. The microscopic images show that the NSs enhance the radiation-induced inhibition by X-ray of cancer cell colony formation (Figure $2 \mathrm{f}$ and Supplementary Figure S6), demonstrating that the combined treatment with $\mathrm{Bi}_{2} \mathrm{Se}_{3}-$ CS-RGD NSs and X-ray reduces cell colony formation in a dosedependent manner.

\section{Cellular uptake and trafficking}

The cellular uptake efficacy is an important regulator in controlling and enhancing the selective cellular uptake of nanomedicine by the cancer cells. ${ }^{52}$ The conjugation of RGD peptides enables antineoplastic drugs to recognize the $\alpha v \beta 3$ integrin receptor, which is abundantly expressed on cervical cells but not on normal tissues, enabling the selectivity. ${ }^{53}$ In this study, to verify the selectivity of the $\mathrm{Bi}_{2} \mathrm{Se}_{3}$-CSRGD NSs between cancer and normal cells, the cellular uptake of the NSs by the cancer (HeLa) and normal (Etc1/E6E7) cells is monitored by analyzing the fluorescence intensity from intracellular coumarin-6loaded NSs. As shown in Figure 3a, the uptake of the $\mathrm{Bi}_{2} \mathrm{Se}_{3}$-CS-RGD NSs by HeLa cells increases with time and is 2.8 times more than that by Etc1/E6E7 normal cells $(12 \mathrm{~h})$. The varying cellular uptake may contribute to the selectivity of the $\mathrm{Bi}_{2} \mathrm{Se}_{3}$-CS-RGD NSs among different cancer and normal cells. Using coumarin- 6 as a probe, the green fluorescence intensity in the cells exposed to the $\mathrm{Bi}_{2} \mathrm{Se}_{3}$-CS-RGD NSs is higher than that for $\mathrm{Bi}_{2} \mathrm{Se}_{3}$-CS NSs (Figure $3 \mathrm{~b}$ ), confirming the important contribution of the RGD peptide to the enhanced cellular uptake of the $\mathrm{Bi}_{2} \mathrm{Se}_{3}$-CS-RGD NSs by cancer cells.

Fluorescent microscopy is employed to evaluate the intracellular trafficking of NSs in the HeLa cells with Lyso-tracker (red) and Hoechst 33342 (blue) to label the lysosomes and nuclei, respectively. As shown in Figure 3c, most of the NSs accumulate in the cell membrane after $2 \mathrm{~h}$, translocate to lysosomes after $4 \mathrm{~h}$, and disperse in the cytoplasm after $6 \mathrm{~h}$. After $12 \mathrm{~h}$, higher accumulation of NSs with bright fluorescence is observed, but no green fluorescence is detected from the cell nuclei, indicating that nuclei are not targeted by the NSs. The $\mathrm{Bi}_{2} \mathrm{Se}_{3}$-CS-RGD NSs shuttle across the cell membrane by endocytosis in $2 \mathrm{~h}$, accumulate gradually in lysosomes, and eventually disperse in the cytoplasm.
Exogenous materials enter cells mainly through direct phagocytosis or receptor-induced phagocytosis, such as by integrin or folic acid receptors, which make them attractive drug targets because their expression level in tumor cells is much higher than that in normal cells. The RGD competing assay is performed to confirm the roles of the RGD-targeting $\alpha v \beta 3$ integrin receptor in internalization of the $\mathrm{Bi}_{2} \mathrm{Se}_{3}-\mathrm{CS}-\mathrm{RGD}$ NSs. As shown in Figures $3 \mathrm{~d}$ and e, RGD pretreatment of the HeLa cells inhibits uptake of the $\mathrm{Bi}_{2} \mathrm{Se}_{3}$-CS-RGD NSs, and the cell viability increases with the addition of RGD in a dosedependent manner. Therefore, in tumor cells, targets on the cell surface are 'passivated' in advance by specific binding of peptides to receptors, which blocks the entrance of the drug into the cell. ${ }^{54}$ These results confirm that selective uptake of $\mathrm{Bi}_{2} \mathrm{Se}_{3}$-CS-RGD NSs by HeLa cells can be traced to integrin-mediated endocytosis.

\section{Mechanism of NS-enhanced X-ray radiotherapy}

Generally, the major mechanisms of cell death induced by anticancer drugs are apoptosis, cell cycle arrest, and/or a combination of these two modes by regulating different signaling pathways. ${ }^{45}$ Flow cytometry is utilized to investigate radiosensitization to X-ray of HeLa cells via the $\mathrm{Bi}_{2} \mathrm{Se}_{3}-\mathrm{CS}-\mathrm{RGD}$ NSs. The DNA histograms in Figure $4 \mathrm{a}$ demonstrate that NSs alone cause G0/G1 phase arrest in the HeLa cells in a dose-dependent manner, and X-ray exposure (8 Gy) induces slight G0/G1 arrest. However, the combination of NSs and X-ray enhances cell apoptosis and cell cycle arrest. For instance, the sub-G1 peak of HeLa cells treated with $80 \mu \mathrm{g} \mathrm{ml}^{-1}$ of the NSs is $10.3 \%$, and it increases to $38.9 \%$ after co-treatment with X-ray. The results demonstrate the important role of cell apoptosis in the radiosensitization effects of the $\mathrm{Bi}_{2} \mathrm{Se}_{3}$-CS-RGD NSs.

Caspases are a family of cystein proteases that play important roles in cell apoptosis. Caspase- 3 acts as a central regulator of cell apoptosis, and caspase- 8 and caspase- 9 are the initiators of death receptormediated and mitochondria-mediated apoptotic pathways, respectively. ${ }^{55}$ To investigate the signaling pathways in $\mathrm{Bi}_{2} \mathrm{Se}_{3}$-CSRGD NS-enhanced radiation-induced apoptosis, a fluorometric assay is applied to monitor the activation of caspase-3, -8 and -9. As shown in Figure $4 \mathrm{~b}$, the $\mathrm{Bi}_{2} \mathrm{Se}_{3}$-CS-RGD NSs cause activation of caspase-3, caspase-8, and caspase- 9 in the HeLa cells after co-treatment with $\mathrm{X}$-ray, indicating that both the death receptor-mediated and mitochondria-mediated pathways are involved in apoptosis. The 
a

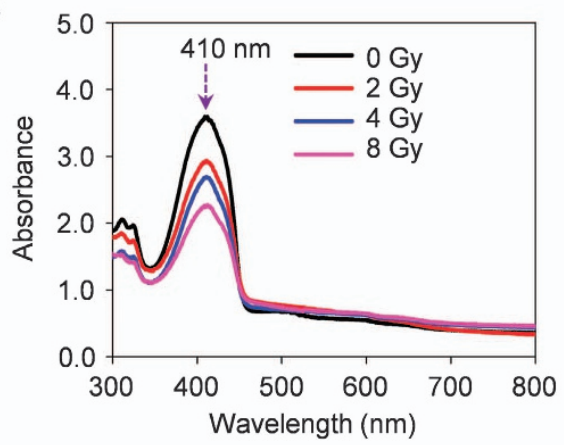

C

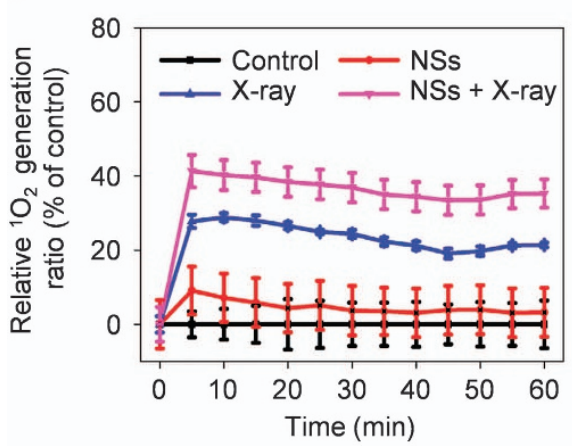

b

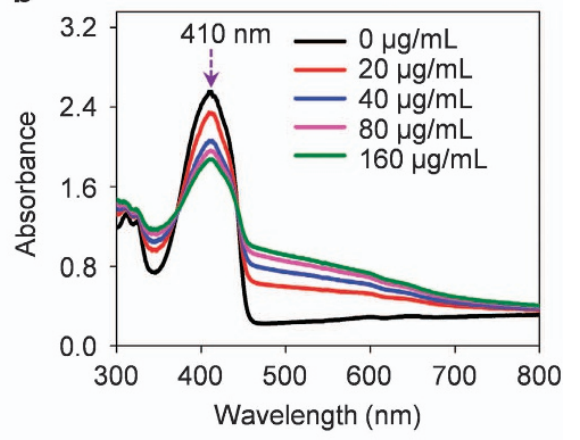

d

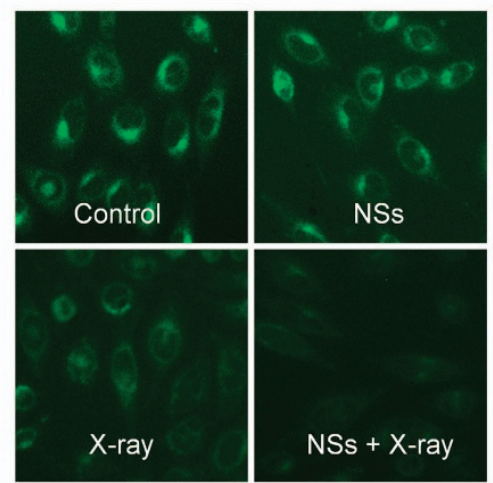

Figure 6 Induction of singlet oxygen overproduction by $\mathrm{Bi}_{2} \mathrm{Se}_{3}-\mathrm{CS}-\mathrm{RGD}$ NSs. (a) The absorbance spectra of DPBF mixed with of $\mathrm{Bi}_{2} \mathrm{Se}_{3}-\mathrm{CS}-\mathrm{RGD} \mathrm{NSs}$ $\left(20 \mu \mathrm{g} \mathrm{ml}^{-1}\right)$ under different dosages of X-rays irradiation. (b) The absorbance spectra of DPBF mixed with specified concentration of $\mathrm{Bi}_{2} \mathrm{Se}_{3}$-CS-RGD NSs under X-ray (8 Gy) irradiation. (c) Time course generation of ${ }^{1} \mathrm{O}_{2}$ in HeLa cells by measuring the absorbance decay of DPBF at $410 \mathrm{~nm}$. Values expressed are means \pm s.d. of triplicates. (d) Fluorescence imaging of ${ }^{1} \mathrm{O}_{2}$ generation in HeLa cells after different treatments. All the cells were marked with DPBF Original magnification: $(\times 20)$.

activity of caspase- 9 is higher than that of caspase-8, suggesting the more important role of mitochondria in caspase-mediated apoptosis.

Mitochondria are the energy factory and are vital in different cellular activities. However, a variety of factors can affect the structure and function of mitochondria and further induce cell apoptosis. ${ }^{56}$ Therefore, the mitochondrial fragmentation and activation of caspase9-dependent apoptosis are assessed to confirm mitochondrial dysfunction resulting from the $\mathrm{Bi}_{2} \mathrm{Se}_{3}$-CS-RGD NSs with radiotherapy. As shown in Figure 4c, Mito-tracker red is used to label the mitochondria, which are present as red threadlike filaments in healthy HeLa cells. The combined treatment induces mitochondria fragmentation and release of constituents into the cytosol, but no significant change is observed for the cells exposed to X-ray or the NSs alone. These results demonstrate the important contribution of mitochondria to the $\mathrm{X}$-ray radiosensitization effects of the $\mathrm{Bi}_{2} \mathrm{Se}_{3}$-CS-RGD NSs.

\section{Activation of ROS-mediated signaling pathways}

Mitochondria are the major source of intracellular free radicals in mammalian cells. Therefore, mitochondrial fragmentation induced by the $\mathrm{Bi}_{2} \mathrm{Se}_{3}$-CS-RGD NSs may trigger ROS overproduction in cancer cells. TrxR, an NADPH-dependent selenoenzyme, is vital to the intracellular redox balance and regulation of apoptosis signaling, and it has been shown that TrxR inhibition can produce ROS-dependent DNA damage responsible for cell growth inhibition. ${ }^{27}$ Moreover, radiation-induced DNA damage is related to the inhibition of TrxR activity. ${ }^{57}$ Here, the combined effects of $\mathrm{Bi}_{2} \mathrm{Se}_{3}-\mathrm{CS}-\mathrm{RGD} \mathrm{NS}$ and $\mathrm{X}$-ray irradiation on the TrxR activity in HeLa cells are studied. As shown in Figure 5a, the NSs and X-ray irradiation alone inhibit the TrxR activity slightly to $98.02 \%$ and $85.41 \%$, respectively. However, the TrxR activity diminishes markedly to $\sim 53.21 \%$ in the HeLa cells after the combined treatment. The western blot analysis results also show that the $\mathrm{Bi}_{2} \mathrm{Se}_{3}$-CS-RGD NSs in combination with X-ray inhibit the expression level of TrxR and Trx in HeLa cells (Figure 5b), providing evidence that decreased expression of TrxR and Trx may contribute to the anticancer efficacy of radiotherapy sensitization by destroying the intracellular redox balance and triggering cell apoptosis.

Reactive oxygen species (ROS) are highly reactive ions and free radicals, including hydrogen peroxide $\left(\mathrm{H}_{2} \mathrm{O}_{2}\right)$, superoxide $\left(\mathrm{O}_{2}{ }^{-}\right)$, hydroxyl radical $(. \mathrm{OH})$, and singlet oxygen $\left({ }^{1} \mathrm{O}_{2}\right)$; these ROS play a vital role in physiology. ${ }^{58}$ Production and enhancement of ROS generation under high-energy radiation is an important factor in cancer radiotherapy. ${ }^{59}$ Dihydroethidium (DHE) is a fluorescence probe used to detect the intracellular superoxide anion $\left(\mathrm{O}_{2}{ }^{-}\right)$, which is the initiator of the free radical chain reaction. Upon receiving highenergy X-ray radiation, high-Z NPs can enhance the $\mathrm{O}_{2}{ }^{-}$conversion to generate $\mathrm{O}_{2}{ }^{-} \cdot / \mathrm{HO}_{2}$., $\mathrm{OH}$., and ${ }^{1} \mathrm{O}_{2} ;{ }^{1} \mathrm{O}_{2}$ is the most prominent and can damage DNA and induce cellular toxicity. ${ }^{51,60}$ Here, ROS generation is investigated in cells treated with the $\mathrm{Bi}_{2} \mathrm{Se}_{3}$-CS-RGD NSs and X-ray using the DHE fluorescence probe. In the cell-free model (Supplementary Figure S7A) and cell model (Supplementary Figure S8A, B), X-ray (8 Gy) alone slightly elevates ROS generation, but ROS generation declines sharply after exposure to the $\mathrm{Bi}_{2} \mathrm{Se}_{3}$-CSRGD NSs alone in a dose-dependent manner (Supplementary Figure $\mathrm{S7B}$ ). It is possible that the $\mathrm{Bi}_{2} \mathrm{Se}_{3}$-CS-RGD NSs are capable of scavenging free radicals, and the total antioxidant activity of the $\mathrm{Bi}_{2} \mathrm{Se}_{3}$-CS-RGD NSs is determined by the $\mathrm{ABTS}^{+}$. scavenging assay. ${ }^{61}$ The detailed time course analysis shown in Supplementary Figure S8C shows that the NSs scavenge the $\mathrm{ABTS}^{+}$in a time- and dose- 
a

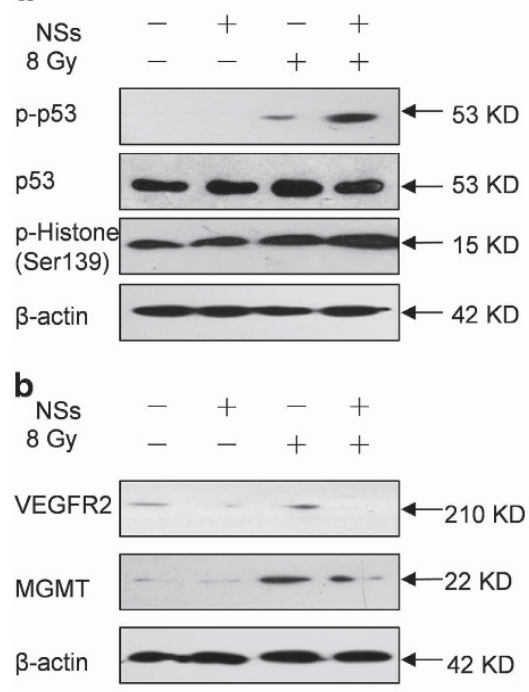

c

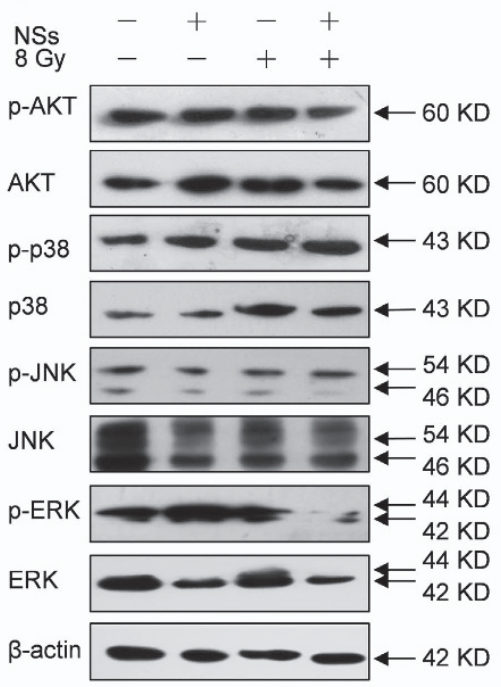

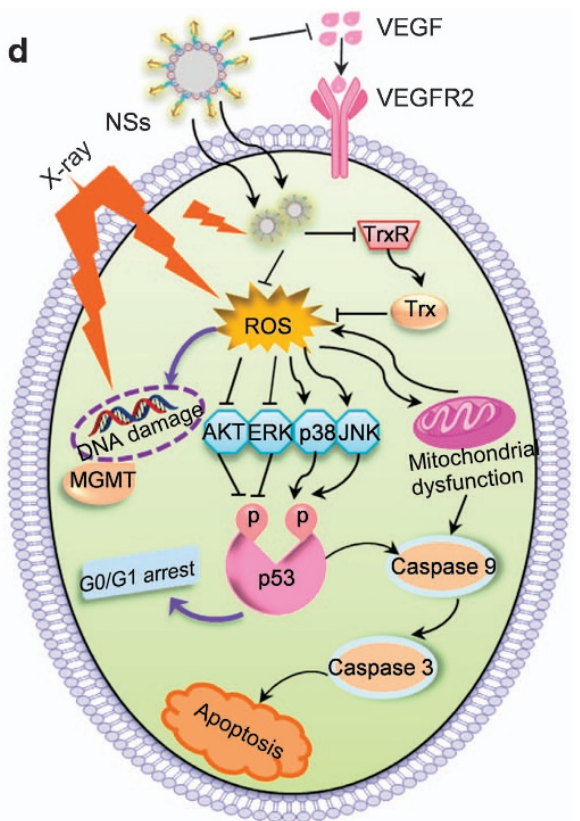

Figure 7 Activation of intracellular apoptotic signaling pathways by $\mathrm{Bi}_{2} \mathrm{Se}_{3}-\mathrm{CS}-\mathrm{RGD}$ NSs and radiation. (a) $\mathrm{Bi}_{2} \mathrm{Se}_{3}-\mathrm{CS}$-RGD NSs enhances radiation-induced activation of the p53 signaling pathway. (b) $\mathrm{Bi}_{2} \mathrm{Se}_{3}-\mathrm{CS}-\mathrm{RGD}$ NSs down-regulates the expression of VEGFR2 and MGMT in HeLa cells. (c) Effects of X-ray and $\mathrm{Bi}_{2} \mathrm{Se}_{3}$-CS-RGD NSs on the expression levels of correlative protein of MAPKs and AKT pathways in HeLa cells. (d) Proposed signaling pathways accounting for cells apoptosis induced by radiation and $\mathrm{Bi}_{2} \mathrm{Se}_{3}$-CS-RGD NSs.

dependent manner. It has been reported that ${ }^{1} \mathrm{O}_{2}$ is formed in irradiated solutions only in the presence of NPs. ${ }^{51}$ The combined treatment reduces the intracellular ROS level compared with the control group, but the level is slightly higher than that for the treatment with $\mathrm{Bi}_{2} \mathrm{Se}_{3}$-CS-RGD NSs alone. We supposed that the NSs become a new source of radiation and emit high energy through a secondary electron effect, enhancing the $\mathrm{O}_{2}{ }^{-}$conversion to generate ${ }^{1} \mathrm{O}_{2}$ in aqueous suspensions due to X-ray absorption. To confirm this hypothesis, the ${ }^{1} \mathrm{O}_{2}$ generation of the NSs is studied using DPBF as the probe molecule in ethanol. As shown in Figures $6 a$ and $b$, the absorption intensities at $\sim 410 \mathrm{~nm}$ for NSs gradually decrease with increasing X-ray irradiation dose and NS concentration. From the calculated curves (Figure 6c), there is no absorption of DPBF in the NSs without irradiation within $60 \mathrm{~min}$; once irradiated by X-rays, the NSs present the maximal efficiency in generating ${ }^{1} \mathrm{O}_{2}$. These results are corroborated by the fluorescence imaging (Figure $6 \mathrm{~d}$ ). Therefore, the NSs enhance the radiosensitivity of HeLa cells to X-ray by producing ${ }^{1} \mathrm{O}_{2}$, inhibiting the TrxR activity and causing an intracellular reactive oxygen species imbalance.

\section{Activation of intracellular apoptotic signaling pathways}

During radiotherapy, radiation-induced DNA damage can lead to cell death by activating different cellular events, ${ }^{62}$ and DNA damage can cause cell death by activating downstream signaling pathways such as p53, MAPKs and AKT.6 ${ }^{63}$ We investigate the expression and phosphorylation of the DNA damage-related proteins in the treated cells, including histone and $\mathrm{p} 53$. The combined treatment elevates the phosphorylated p53 compared to X-ray or $\mathrm{Bi}_{2} \mathrm{Se}_{3}$-CS-RGD NS treatment alone, but the total p53 expression remains unchanged (Figure 7a). Moreover, phosphorylation of histone at the Ser 139 site, an important marker of DNA double-stranded break, is upregulated in response to the combined treatment, indicating the involvement of the DNA damage-mediated p53 pathway in cell apoptosis.
Cancer cells have the ability to repair DNA double strand breaks in radiation-induced lesions and reverse drug-induced cell damage. ${ }^{64}$ Therefore, the expression levels of the DNA repair proteins VEGFR 2 and MGMT, the recovery proteins of cancer cells after radiation, are studied. As shown in Figure 7b, X-ray irradiation up-regulates VEGFR 2 and MGMT, whereas the $\mathrm{Bi}_{2} \mathrm{Se}_{3}$-CS-RGD NSs and combination treatment reduce the expression levels, inhibiting the self-repair capability of the HeLa cells. Mitogen-activated protein kinases (MAPKs), including p38, ERK, and JNK, and AKT kinase are important regulators of cell proliferation, growth, and apoptosis in response to drug treatment. The combined treatment is found to produce different effects on the phosphorylation status of MAPKs and AKT in HeLa cells (Figure 7c); phosphorylation of the pro-apoptotic kinase p38 displays a trend of upregulation, whereas that of the antiapoptotic kinases AKT and ERK is suppressed and that of JNK is not affected. It can be inferred that the $\mathrm{Bi}_{2} \mathrm{Se}_{3}$-CS-RGD NSs enhance $\mathrm{X}$-ray-induced DNA damage and suppress the cell self-repair capability via the p53, MAPKs and AKT signaling pathways (Figure 7d).

\section{In vivo imaging and biodistribution investigations}

In PAI, which offers high spatial resolution, the optical energy absorbed by light-absorbing tissues or contrast agents with thermal expansion creates reflected ultrasound signals. ${ }^{65,66}$ PAI has the advantage of deep tissue penetration as a result of the ultrasonic wave produced by the pulsed laser ${ }^{67,68}$ and can be utilized to investigate tumor-targeting effects. The bare $\mathrm{Bi}_{2} \mathrm{Se}_{3} \mathrm{NSs}$ and $\mathrm{Bi}_{2} \mathrm{Se}_{3}$-CS-RGD NSs are injected intravenously $\left(1 \mathrm{mg} \mathrm{ml}^{-1}, 0.1 \mathrm{ml}\right)$ into tumor-bearing nude mice, and the PA images are acquired $2-18 \mathrm{~h}$ post injection. As shown in Figure $8 \mathrm{a}$, gradually increasing PA signals of the $\mathrm{Bi}_{2} \mathrm{Se}_{3}$-CSRGD NSs are detected from the tumor tissue, and the tumor outline becomes increasingly clear during the first $6 \mathrm{~h}$ (PA signals $\sim 271 \mathrm{au}$, Supplementary Figure S9A), indicating time-dependent accumulation of the NSs at the tumor. The PA signal then decreases, suggesting clearance of the NSs from the cancer cells. A post-injection time point 

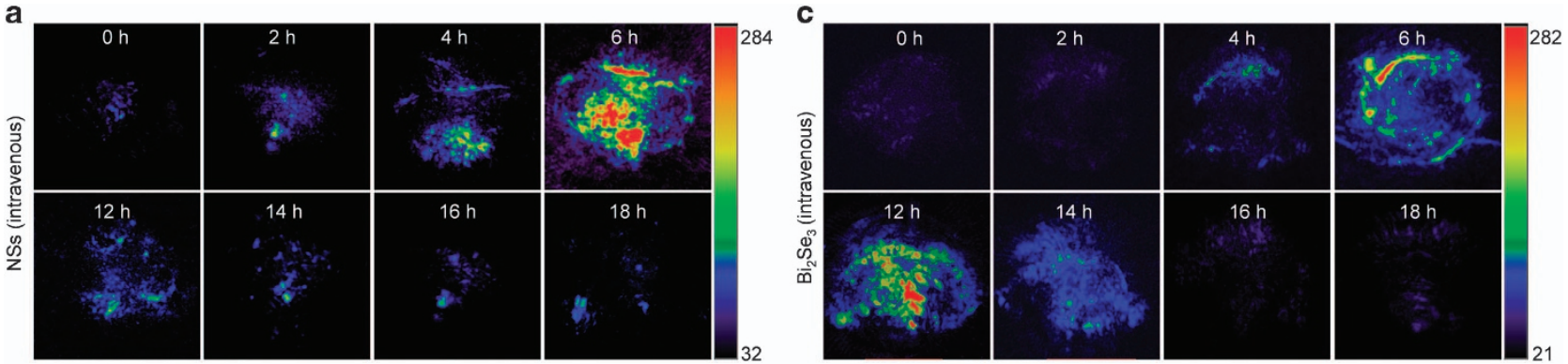

b
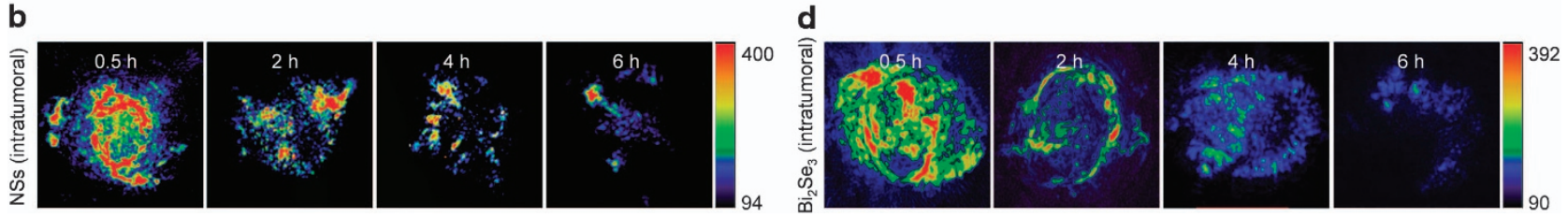

Figure $8 \mathrm{PAl}$ of tumor sites at different time post-injection of $\mathrm{Bi}_{2} \mathrm{Se}_{3}-\mathrm{CS}-\mathrm{RGD}$ NSs with different injection modes: (a) intravenous injection and (b) intratumoral injection. PAl of tumor sites at different time post-injection of $\mathrm{Bi}_{2} \mathrm{Se}_{3} \mathrm{NSs}$ with different injection modes: (c) intravenous injection and (d) intratumoral injection.
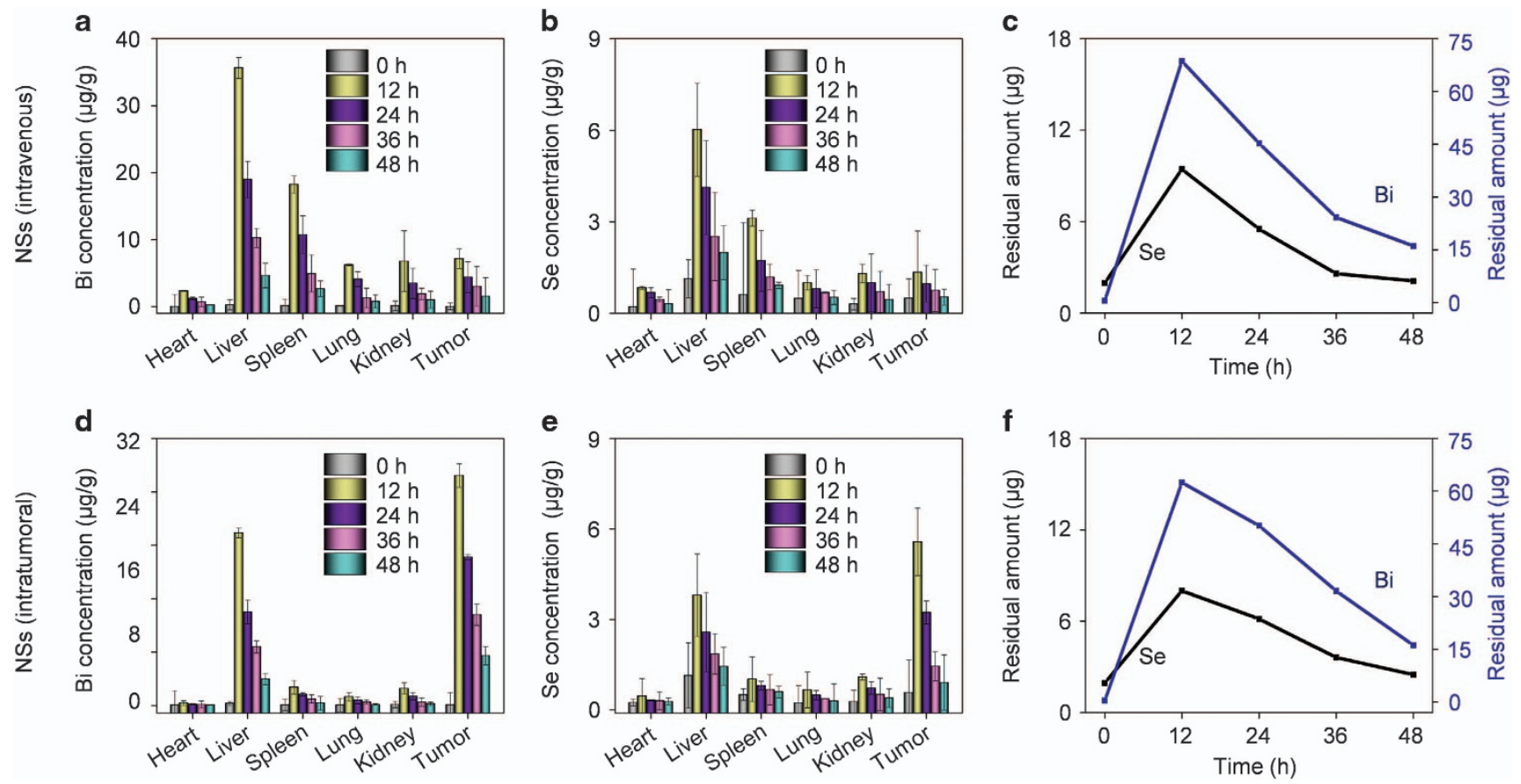

Figure 9 Biodistribution and clearance properties of $\mathrm{Bi}_{2} \mathrm{Se}_{3}-\mathrm{CS}-\mathrm{RGD}$ NSs in vivo at the different time points of $12,24,36$, and $48 \mathrm{~h}$ after (a-c) intravenous injection and (d-f) intratumoral injection. (a, d) Bi concentrations and (b, e) Se concentrations in different organs. (c, f) Residual Bi and Se amounts plotted versus time.

of $6 \mathrm{~h}$ is selected for the subsequent $\mathrm{X}$-ray radiosensitization experiments. The tumor-targeting effects by intratumoral injection are also compared. As shown in Figure 8b, the PA signal from the tumor site lasts up to $6 \mathrm{~h}$ after intratumoral injection of the $\mathrm{Bi}_{2} \mathrm{Se}_{3}$-CS-RGD NSs at the same concentration as intravenous injection. The PA images of the bare $\mathrm{Bi}_{2} \mathrm{Se}_{3}$ NSs are shown in Figures $8 \mathrm{c}$ and d. After intravenous injection of the $\mathrm{Bi}_{2} \mathrm{Se}_{3} \mathrm{NSs}$, the largest PA signal intensity is only $\sim 193$ $\mathrm{au}$ and is weaker than that of the $\mathrm{Bi}_{2} \mathrm{Se}_{3}-\mathrm{CS}-\mathrm{RGD}$ NSs. The corresponding time point for the largest PA signal is $12 \mathrm{~h}$, longer than that of the $\mathrm{Bi}_{2} \mathrm{Se}_{3}$-CS-RGD NSs (Supplementary Figure S9A). After intratumoral injection of the $\mathrm{Bi}_{2} \mathrm{Se}_{3} \mathrm{NSs}$, the PA signal intensity from the tumor area declines rapidly, and faint signals can be detected at $6 \mathrm{~h}$ post-injection (Supplementary Figure S9B). These results demonstrate that the RGD-decorated $\mathrm{Bi}_{2} \mathrm{Se}_{3}$ NSs have more efficient tumor-targeting ability and have longer residence time than the bare $\mathrm{Bi}_{2} \mathrm{Se}_{3} \mathrm{NSs}$.

The biodistribution and clearance properties of nanomaterials are crucial for the rational design of nanomedicine in advanced cancer therapy. To explore the biodistribution profile of the $\mathrm{Bi}_{2} \mathrm{Se}_{3}-\mathrm{CS}-\mathrm{RGD}$ NSs in vivo, inductively coupled plasma mass spectrometry is employed to determine the concentrations of $\mathrm{Bi}$ and $\mathrm{Se}$ in tumor tissues and main organs at $0,12,24,36$ and $48 \mathrm{~h}$ after injection of the NSs into HeLa tumor-bearing nude mice. As shown in Figure $9 \mathrm{a}$, the original amounts of $\mathrm{Bi}$ in the different organs of the 


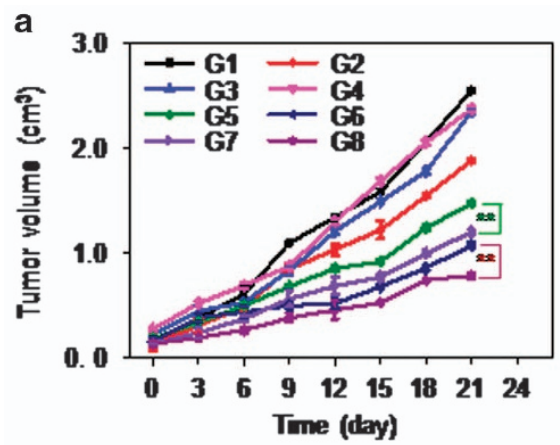

d
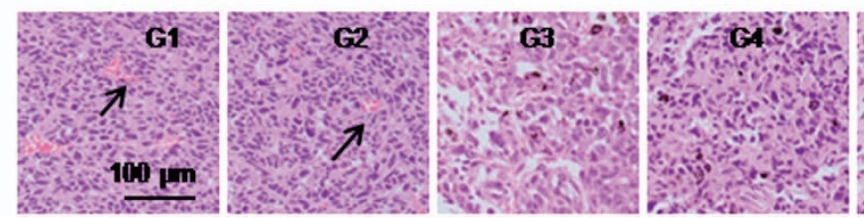
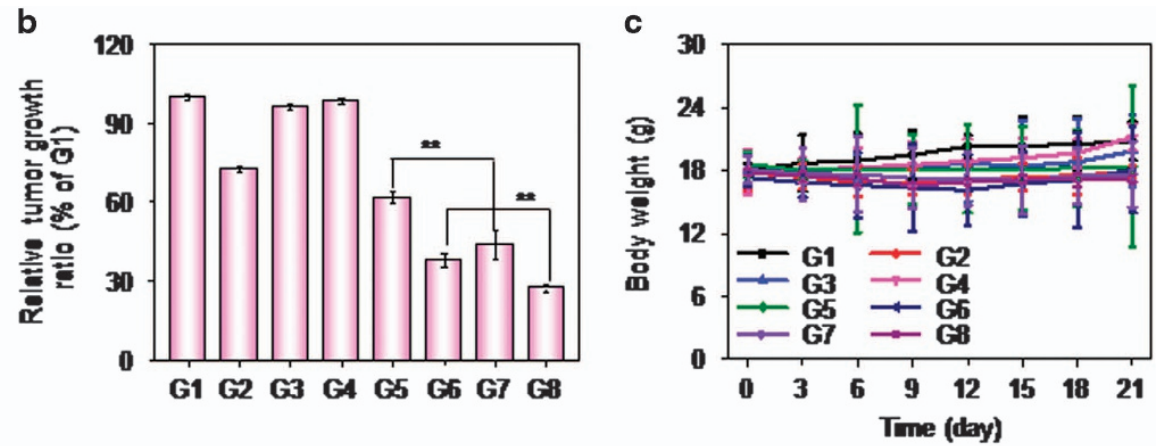

Figure 10 In vivo radio-sensitization effects of $\mathrm{Bi}_{2} \mathrm{Se}_{3}-\mathrm{CS}-\mathrm{RGD}$ NSs. (a) Time-course studies of the tumor volume change of HeLa tumor-bearing mice following different treatments. (b) Relative tumor growth inhibition ratio of different groups of HeLa tumor-bearing mice at 21 day. (c) Body weight change of HeLa tumor-bearing mice following different treatments. (d) Microscopy images of H\&E-stained tumor slices collected from different groups of HeLa tumor-

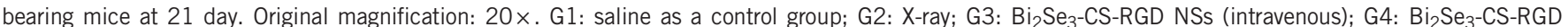
$\mathrm{NSs}$ (intratumoral); G5: $\mathrm{Bi}_{2} \mathrm{Se}_{3} \mathrm{NSs}$ (intravenous) + X-ray; G6: $\mathrm{Bi}_{2} \mathrm{Se}_{3} \mathrm{NSs}$ (intratumoral) + X-ray; $\mathrm{G} 7: \mathrm{Bi}_{2} \mathrm{Se}_{3}-\mathrm{CS}-\mathrm{RGD} \mathrm{NSs}$ (intravenous) + X-ray; G8: Bi $2 \mathrm{Se}_{3}-$ CS-RGD NSs (intratumoral) + X-ray. Each value represents means \pm s.d. $(n=3)$. Significant difference between the different treatment groups is indicated by $* * P<0.01$

mice are $0.032 \mu \mathrm{g} \mathrm{g}^{-1}$ (heart), $0.25 \mu \mathrm{g} \mathrm{g}^{-1}$ (liver), $0.15 \mu \mathrm{g} \mathrm{g}^{-1}$ (spleen),

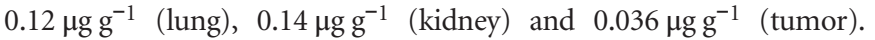
After injection of the NSs, they aggregate mainly in the liver, spleen and kidney, and the lung and heart show relatively low Bi concentrations. Moreover, high concentrations of $\mathrm{Bi}$ are detected in the tumor due to the active targeting effect attributed to the RGD peptides. The Bi concentrations decrease from $35.64{\mu \mathrm{gg}^{-1}}^{-1}$ (liver), $18.25 \mu \mathrm{g} \mathrm{g}^{-1}$

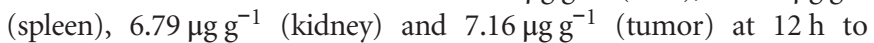

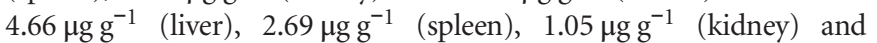
$1.58 \mathrm{\mu g} \mathrm{g}^{-1}$ (tumor) at $48 \mathrm{~h}$ after intravenous injection. The Se biodistribution in different tissues and tumors of the nude mice before injection of the $\mathrm{Bi}_{2} \mathrm{Se}_{3}$-CS-RGD NSs are also measured. As shown in Figure 9b, the original amounts of Se in the different organs

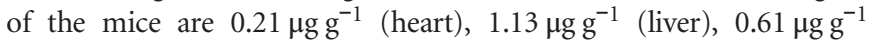

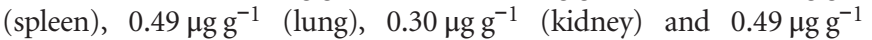
(tumor). At $12 \mathrm{~h}$ post-injection, Se shows the highest accumulation in the liver, spleen, kidney and tumor, with concentrations of 6.02,

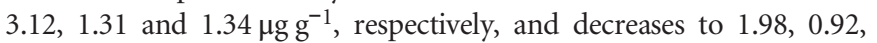
0.45 and $0.53 \mu \mathrm{g} \mathrm{g}^{-1}$ at $48 \mathrm{~h}$, respectively. To investigate the clearance of the NSs, the time-dependent residual amounts of $\mathrm{Bi}$ and Se in the mice are calculated by summing the amount of $\mathrm{Bi}$ and $\mathrm{Se}$ in all the tissues from the injected $\mathrm{Bi}_{2} \mathrm{Se}_{3}$-CS-RGD NSs (Figure 9c). The initial total amounts of $\mathrm{Bi}$ and Se are 100.1 and $39.45 \mu \mathrm{g}$, respectively. As expected, the Bi concentrations decrease to $68.62 \mu \mathrm{g}$ after $12 \mathrm{~h}$ and to $16.09 \mu \mathrm{g}$ after $48 \mathrm{~h}$, and similar behavior is observed for Se. The residual amount is $9.44 \mu \mathrm{g}$ after $12 \mathrm{~h}$ and decreases to $2.11 \mu \mathrm{g}$ after $48 \mathrm{~h}$. Both the biodistribution and clearance efficiency of Bi and Se after intratumoral injection are similar to those after intravenous injection, and much larger concentrations are present at the tumor (Figures $9 \mathrm{~d}-\mathrm{f}$ ). The liver and spleen are the dominant organs participating in the metabolism of the NSs, and their cancertargeting effects and subsequent excretion are verified experimentally. The biodistribution and clearance of the bare $\mathrm{Bi}_{2} \mathrm{Se}_{3} \mathrm{NSs}$ in vivo are also investigated (Supplementary Figure S10). Compared to the $\mathrm{Bi}_{2} \mathrm{Se}_{3}$-CS-RGD NSs, the bare $\mathrm{Bi}_{2} \mathrm{Se}_{3}$ NSs show similar clearance profiles, but there is much less accumulation in the tumor, confirming that RGD decoration leads to a more efficient tumor targeting ability of the $\mathrm{Bi}_{2} \mathrm{Se}_{3}$ NSs.

\section{In vivo radiosensitization effects}

The in vivo cancer radiosensitization activity of the $\mathrm{Bi}_{2} \mathrm{Se}_{3} \mathrm{NSs}$ and $\mathrm{Bi}_{2} \mathrm{Se}_{3}$-CS-RGD NSs is studied using HeLa tumor-bearing nude mice. Based on the PAI results, the samples are injected intravenously $6 \mathrm{~h}$ in advance and intratumorally within $0.5 \mathrm{~h}$ before injection with $1 \mathrm{mg} \mathrm{ml}^{-1}$ and $0.1 \mathrm{ml}$ doses. The mice are irradiated by X-ray at a dose of 4 Gy using a 2-cm-thick lead plate with appropriate holes to protect other parts of the body from radiation. The changes in the tumor volume and body weight are determined for 21 days post injection (Figure 10). In the control groups treated with the $\mathrm{Bi}_{2} \mathrm{Se}_{3}$-CS-RGD NSs alone, the tumor volume increases with time, and X-ray irradiation alone inhibits tumor growth from 2.55 to $1.78 \mathrm{~cm}^{3}$. When the mice are treated with both X-ray and $\mathrm{Bi}_{2} \mathrm{Se}_{3} \mathrm{NSs}$ by intravenous and intratumoral injection, the tumor volume decreases to $1.48 \mathrm{~cm}^{3}$ (G5) and $1.08 \mathrm{~cm}^{3}$ (G6), respectively. In comparison, better therapeutic effects are achieved from the X-ray and $\mathrm{Bi}_{2} \mathrm{Se}_{3}$-CS-RGD cotreatment groups, in which intravenous and intratumoral injection reduce the tumor volume to $1.20 \mathrm{~cm}^{3}$ (G7) and $0.79 \mathrm{~cm}^{3}$ (G8), respectively. Therefore, the in vivo radiotherapy efficacy of $\mathrm{Bi}_{2} \mathrm{Se}_{3} \mathrm{NSs}$ is enhanced by targeted modification with RGD peptide. The excellent active targeting ability of the $\mathrm{Bi}_{2} \mathrm{Se}_{3}$-CS-RGD NSs results in accumulation of $\mathrm{Bi}$ in the tumor, acting as a radiosensitizer to inhibit tumor growth. In addition, the X-ray treatment reduces the body weight of the treated mice, but no decline is observed for the NS groups, suggesting that the $\mathrm{Bi}_{2} \mathrm{Se}_{3}$-CS-RGD NSs have low in vivo toxicity.

MRI is a powerful nondestructive diagnostic tool that provides high spatial resolution in soft tissues and morphological details and multifunctional information about lesions. ${ }^{69}$ This technique is employed in this study to confirm the radiosensitization properties of the $\mathrm{Bi}_{2} \mathrm{Se}_{3}$ CS-RGD NSs. The $T_{2}$-weighted MR images of HeLa tumors using an EG 1.5 T clinical MR scanner equipped with a small animal imaging 

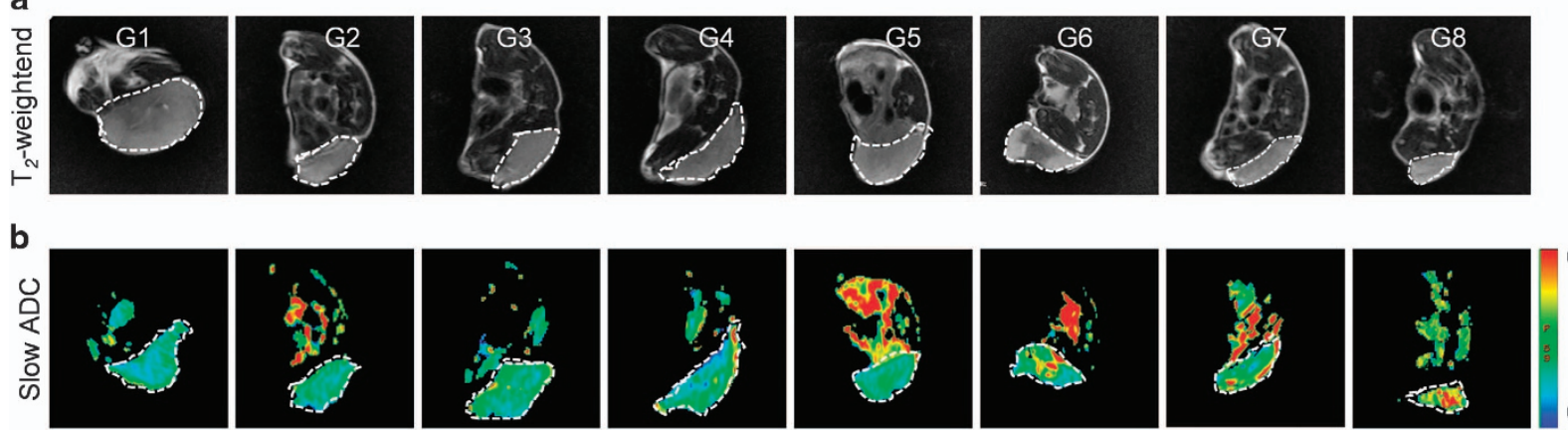

0.00105
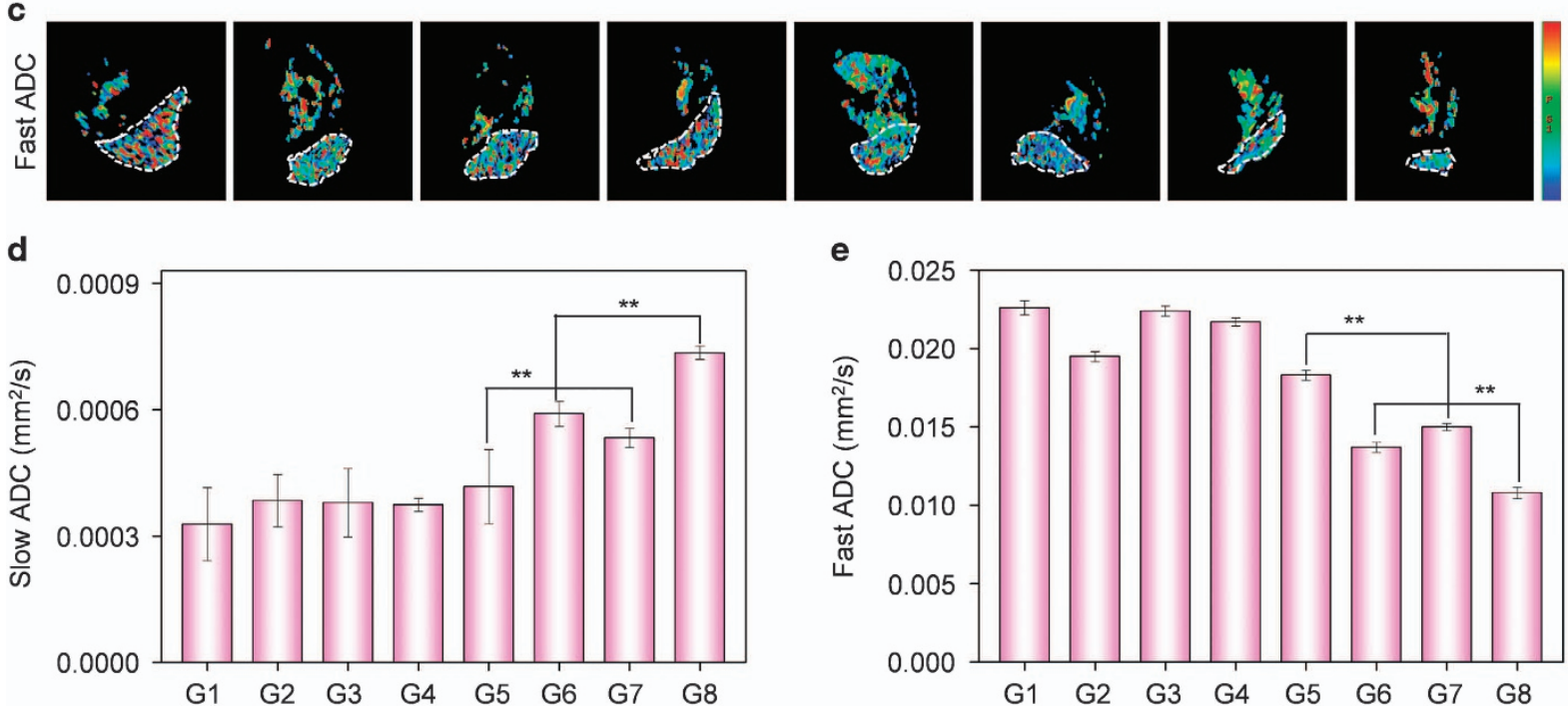

Figure $11 T_{2}$-weighted MR images of HeLa-bearing mice after various treatments for 21 day. (a) $T_{2}$-weighted, (b) Slow ADC and (c) Fast ADC. Quantification the pseudo-color signals of Slow ADC (d) and Fast ADC (e) for the tumor site. The tumor sites are in the back, and circled by a white dashed line. G1: saline as a control group; G2: X-ray; G3: $\mathrm{Bi}_{2} \mathrm{Se}_{3}-\mathrm{CS}-\mathrm{RGD}$ NSs (intravenous); G4: $\mathrm{Bi}_{2} \mathrm{Se}_{3}-\mathrm{CS}-\mathrm{RGD}$ NSs (intratumoral); G5: Bi $2 \mathrm{Se}_{3} \mathrm{NSs}$ (intravenous) + X-ray; G6: $\mathrm{Bi}_{2} \mathrm{Se}_{3} \mathrm{NSs}$ (intratumoral) + X-ray; G7: $\mathrm{Bi}_{2} \mathrm{Se}_{3}-\mathrm{CS}-\mathrm{RGD} \mathrm{NSs}$ (intravenous) + X-ray; G8: $\mathrm{Bi}_{2} \mathrm{Se}_{3}-\mathrm{CS}-\mathrm{RGD} \mathrm{NSs}$ (intratumoral) + X-ray. Significant difference between the different treatment groups is indicated by $* * P<0.01$.

coil are shown in Figure 11a. After 21 days, darkening effects are observed in the tumors in the $\mathrm{Bi}_{2} \mathrm{Se}_{3}$-CS-RGD NSs and X-ray co-treated groups, indicating a high tumor-active targeting effect. The Slow $\mathrm{ADC}$ and Fast $\mathrm{ADC}$ signals reflect the necrotic degree in the tumor area and blood flow in the tumor vessels. The $\mathrm{Bi}_{2} \mathrm{Se}_{3} \mathrm{NSs}+$ $\mathrm{X}$-ray co-treatment groups (G5, G6) show little changes in Slow ADC (Figure 11b) and Fast ADC (Figure 11c) compared with the control group. However, a stronger Slow ADC signal and a weaker Fast ADC signal at the tumor sites can be observed in the $\mathrm{Bi}_{2} \mathrm{Se}_{3}$-CS-RGD NSs combined with X-ray treatment groups (G7, G8). This effect is confirmed by quantifying the relative signal intensity (Figures 11d and e), revealing that the $\mathrm{Bi}_{2} \mathrm{Se}_{3}$-CS-RGD NSs reduce the cancer cell activity and density more than bare $\mathrm{Bi}_{2} \mathrm{Se}_{3} \mathrm{NSs}$ after the co-treatment, consistent with the pathological H\&E staining results (Figure 10d). Overall, these results indicate that the $\mathrm{Bi}_{2} \mathrm{Se}_{3}$-CS-RGD NSs possess unambiguous advantages over the bare $\mathrm{Bi}_{2} \mathrm{Se}_{3}$ NSs in radiotherapy of cervical cancer due to conjugation of the cancer-targeting RGD peptide.

To further assess the possible in vivo toxicity, the mice in different treatment groups are sacrificed and subjected to hematological analysis after 21 days. As shown in Figure 12a, compared to healthy nude mice, the HeLa xenograft nude mice show reduced plasma glucose (GLU), increased low-density lipoprotein (LDLC), and acute liver and renal dysfunction, as manifested by decreases in the total protein (TP) and uric acid (UA) and increases in aspartate aminotransferase (AST) and blood urea nitrogen (BUN). The $\mathrm{Bi}_{2} \mathrm{Se}_{3}$-CS-RGD NSs combined with $\mathrm{X}$-ray treatment does not cause hepatic damage compared to healthy mice, as shown by the hepatic function markers (TP, AST). The renal function markers (UA and BUN) also recover to the levels of normal mice after the combined treatment. However, treatment of the nude mice with $\mathrm{Bi}_{2} \mathrm{Se}_{3} \mathrm{NSs}$ results in toxicity to the liver, as reflected by the changes in the blood biochemical values, especially AST. Therefore, these results demonstrate that RGD conjugation is an effective strategy to reduce the in vivo toxicity of $\mathrm{Bi}_{2} \mathrm{Se}_{3} \mathrm{NSs}$. Histological analysis of the major organs, such as the heart, liver, spleen, lung and kidney, is performed on the treatment groups. As shown in Figure 12b, several dark spots are observed on the liver after $\mathrm{Bi}_{2} \mathrm{Se}_{3} \mathrm{NS}$ treatment, which was due to the cellular uptake of liver macrophage through phagocytosis and accumulation in the liver sinus (Supplementary Figure S11). No other notable organ damage or inflammatory lesions can be detected. In the $\mathrm{Bi}_{2} \mathrm{Se}_{3}$-CS-RGD NS treatment, no dark spots could be detected in the hepatic sinusoid, verifying its selectivity. These results show that covalent conjugation of RGD improves $\mathrm{Bi}_{2} \mathrm{Se}_{3} \mathrm{NS}$ accumulation in tumor tissues and reduces the in vivo toxicity, making $\mathrm{Bi}_{2} \mathrm{Se}_{3}-\mathrm{CS}-\mathrm{RGD} \mathrm{NSs}$ safe in cancer radiotherapy.

\section{CONCLUSION}

Ultrathin $\mathrm{Bi}_{2} \mathrm{Se}_{3}$-CS-RGD NSs with excellent tumor targeting ability and potent radiosensitization efficiency are constructed for imaging- 
a
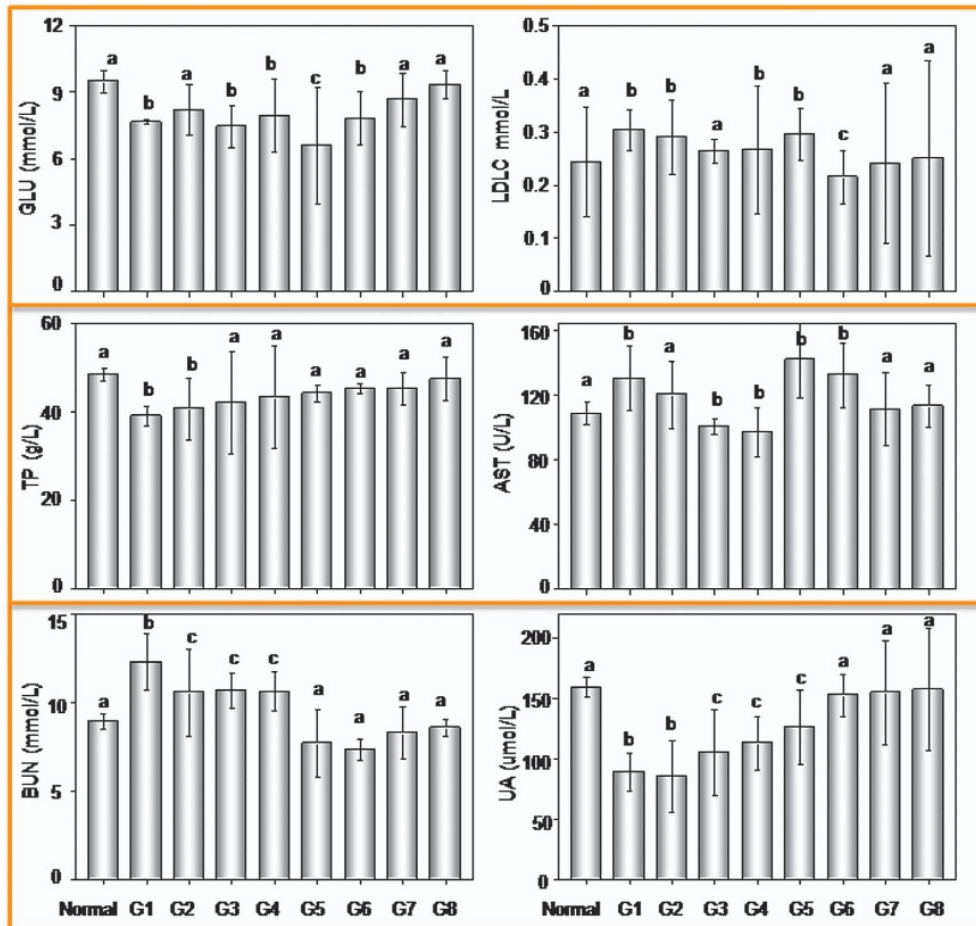
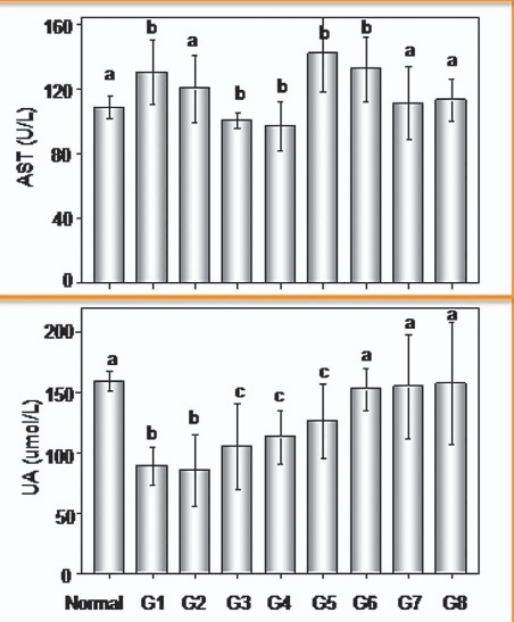

b

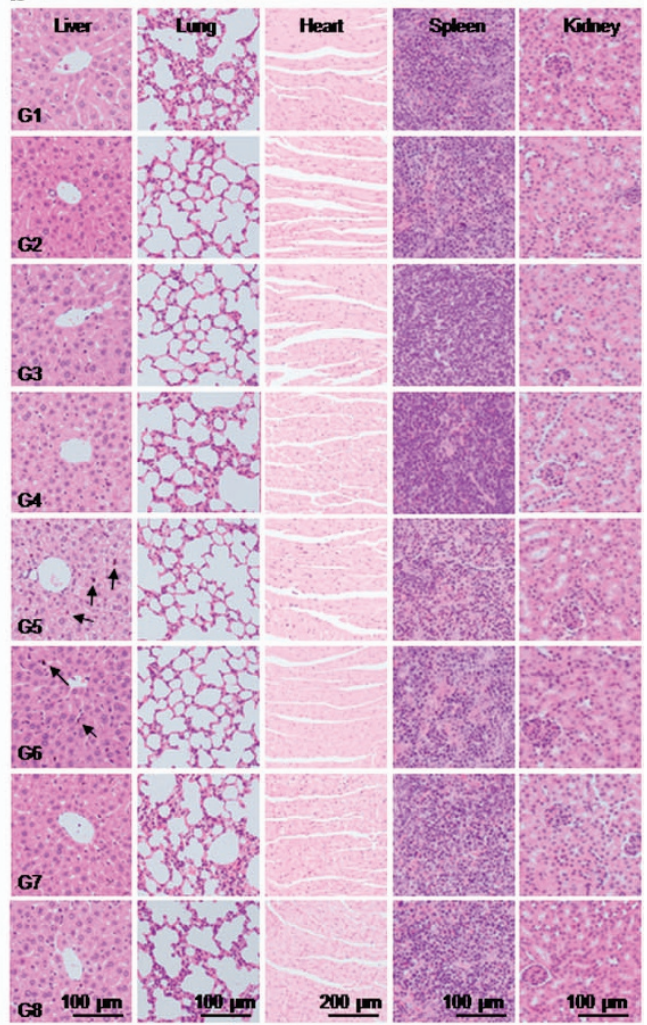

Figure 12 (a) Hematological analysis of normal and different treatments nude mice for 21 days. Serum biochemistry indexes including blood glucose (GLU), low density lipoprotein (LDLC), total protein (TP), aspartate aminotransferase (AST), blood urea nitrogen (BUN) and uric acid (UA). Bars with different characters $(a, b$, and $c)$ are statistically different at ${ }^{*} P<0.05$ level. Values expressed are means \pm SD of triplicates. (b) Histology analysis of the major organs collected from different treatments of HeLa xenograft nude mice after 21 day. Liver, lung, spleen, and kidney original magnification: $20 \times$, heart original magnification: $10 \times$. G1: saline as a control group; G2: X-ray; G3: $\mathrm{Bi}_{2} \mathrm{Se}_{3}-\mathrm{CS}-\mathrm{RGD}$ NSs (intravenous); G4: $\mathrm{Bi}_{2} \mathrm{Se}_{3}-\mathrm{CS}-\mathrm{RGD}$ NSs (intratumoral); G5: $\mathrm{Bi}_{2} \mathrm{Se}_{3} \mathrm{NSs}$ (intravenous) +X-ray; G6: $\mathrm{Bi}_{2} \mathrm{Se}_{3} \mathrm{NSs}$ (intratumoral) +X-ray; G7: $\mathrm{Bi}_{2} \mathrm{Se}_{3}-\mathrm{CS}-\mathrm{RGD}$ NSs (intravenous) +X-ray; G8: Bi $\mathrm{Se}_{3}-\mathrm{CS}-\mathrm{RGD}$ NSs (intratumoral) + X-ray.

guided cancer radiotherapy. The $\mathrm{Bi}_{2} \mathrm{Se}_{3}-\mathrm{CS}-\mathrm{RGD} \mathrm{NSs}$ with $\mathrm{X}$-ray irradiation inhibit HeLa cell growth by inducing G0/G1 cycle arrest and mitochondria-mediated intrinsic cell apoptosis. The $\mathrm{Bi}_{2} \mathrm{Se}_{3}$-CSRGD NSs enhance the sensitivity of cancer cells to X-ray-induced apoptosis by inhibiting TrxR and activating downstream ROS-mediated signaling pathways to regulate cell apoptosis. In the nude mice model, the RGD coating enables the $\mathrm{Bi}_{2} \mathrm{Se}_{3}$ NSs to rapidly aggregate in the tumor regions, enabling efficient PAI of the entire tumor to facilitate radiotherapy of cervical cancer. Nondestructive MR imaging demonstrates increased tumor tissue necrosis, reduced blood flow in the tumor vessels, and reduced cancer cell activity and density after the combined $\mathrm{Bi}_{2} \mathrm{Se}_{3}$-CS-RGD NSs and X-ray treatment, which is more efficient than bare $\mathrm{Bi}_{2} \mathrm{Se}_{3}$ NSs alone. The $\mathrm{Bi}_{2} \mathrm{Se}_{3} \mathrm{NSs}$ after RGD decoration show much better in vivo biocompatibility and are efficiently expelled from the body after $48 \mathrm{~h}$ post-injection. No evident damage or inflammatory lesions is observed in the major organs, including the heart, liver, spleen, lung and kidney, in the hematological and histological analyses. The $\mathrm{Bi}_{2} \mathrm{Se}_{3} \mathrm{NSs}$ with RGD modification have great potential as an effective and safe in vivo theranostic agent for next-generation cancer radiotherapy.

\section{CONFLICT OF INTEREST}

The authors declare no conflict of interest.

\section{ACKNOWLEDGEMENTS}

This work was supported by the Guangdong Special Support Program and Guangdong Frontier Key Technological Innovation Special Funds (2014B050505012), the Science Foundation for Distinguished Young Scholars of Guangdong Province (2013050014667), the Natural Science Foundation of China (21371076), the National High-level personnel of special support program (2014189), the YangFan Innovative \& Entepreneurial Research Team Project (201312H05), Fundamental Research Funds for the Central Universities and Hong Kong Research Grants Council General Research Funds (GRF) No. CityU 11301215.

\section{PUBLISHER'S NOTE}

Springer Nature remains neutral with regard to jurisdictional claims in published maps and institutional affiliations.

1 Li, M. F., Zhao, Q., Yi, X., Zhong, X. Y., Song, G. S., Chai, Z. F., Liu, Z. A. \& Yang, K. Au@MnS@ZnS core/shell/shell nanoparticles for magnetic resonance imaging and enhanced cancer radiation therapy. ACS Appl. Mater. Inter. 8, 9557-9564 (2016).

2 Yang, Y. S., Carney, R. P., Stellacci, F. \& Irvine, D. J. Enhancing radiotherapy by lipid nanocapsule-mediated delivery of amphiphilic gold nanoparticles to intracellular membranes. ACS Nano 8, 8992-9002 (2014).

3 Dou, Y., Guo, Y., Li, X., Li, X., Wang, S., Wang, L., Lv, G., Zhang, X., Wang, H., Gong, X. \& Chang, J. Size-tuning ionization to optimize gold nanoparticles for simultaneous enhanced CT imaging and radiotherapy. ACS Nano 10, 2536-2548 (2016).

4 Au, K. M., Min, Y. Z., Tian, X., Zhang, L. Z., Perello, V., Caster, J. M. \& Wang, A. Z. Improving cancer chemoradiotherapy treatment by dual controlled release of wortmannin and docetaxel in polymeric nanoparticles. ACS Nano 9, 8976-8996 (2015). 
5 Dufort, S., Bianchi, A., Henry, M., Lux, F., Le Duc, G., Josserand, V., Louis, C., Perriat, P., Cremillieux, Y., Tillement, O. \& Coll, J. L. Nebulized gadolinium-based nanoparticles: a theranostic approach for lung tumor imaging and radiosensitization. Small 11 215-221 (2015).

6 Guler, E., Akbulut, H., Geyik, C., Yilmaz, T., Gumus, Z. P., Barlas, F. B., Ahan, R. E., Demirkol, D. O., Yamada, S., Endo, T., Timur, S. \& Yagci, Y. Complex structured fluorescent polythiophene graft copolymer as a versatile tool for imaging, targeted delivery of paclitaxel, and radiotherapy. Biomacromolecules 17, 2399-2408 (2016).

7 Le Duc, G., Miladi, I., Alric, C., Mowat, P., Brauer-Krisch, E., Bouchet, A., Khalil, E., Billotey, C., Janier, M., Lux, F., Epicier, T., Perriat, P., Roux, S. \& Tillement, O. Toward an image-guided microbeam radiation therapy using gadolinium-based nanoparticles. ACS Nano 5, 9566-9574 (2011)

8 Tamborini, M., Locatelli, E., Rasile, M., Monaco, I., Rodighiero, S., Corradini, I., Franchini, M. C., Passoni, L. \& Matteoli, M. A combined approach employing chlorotoxin-nanovectors and low dose radiation to reach infiltrating tumor niches in glioblastoma. ACS Nano 10, 2509-2520 (2016).

9 Brown, J. M. \& William, W. R. Exploiting tumour hypoxia in cancer treatment. Nat. Rev. Cancer 4, 437-447 (2004).

10 Peters, K. B. \& Brown, J. M. Tirapazamine: a hypoxia-activated topoisomerase II poison. Cancer Res. 62, 5248-5253 (2002).

11 Wardman, P. Chemical radiosensitizers for use in radiotherapy. Eur. J. Cancer Clin. Oncol. 19, 397-417 (2007).

12 Collingridge, D. R. \& Rockwell, S. Pentoxifylline improves the oxygenation and radiation response of BA1112 rat rhabdomyosarcomas and EMT6 mouse mammary carcinomas. Int. J. Cancer 90, 256-264 (2000).

13 Lin, M. H., Hsu, T. S., Yang, P. M., Tsai, M. Y., Perng, T. P. \& Lin, L. Y. Comparison of organic and inorganic germanium compounds in cellular radiosensitivity and preparation of germanium nanoparticles as a radiosensitizer. Int. J. Radiat. Biol. 85 214-226 (2009).

14 Klein, S., Sommer, A., Distel, L. V. R., Hazemann, J. L., Kroner, W., Neuhuber, W., Muller, P., Proux, O. \& Kryschi, C. Superparamagnetic iron oxide nanoparticles as novel X-ray enhancer for low-dose radiation therapy. J. Phys. Chem. B 118 6159-6166 (2014).

15 Klein, S., Sommer, A., Distel, L. V. R., Neuhuber, W. \& Kryschi, C. Superparamagnetic iron oxide nanoparticles as radiosensitizer via enhanced reactive oxygen species formation. Biochem. Biophys. Res. Commun. 425, 393-397 (2012).

16 Rima, W., Sancey, L., Aloy, M. T., Armandy, E., Alcantara, G. B., Epicier, T., Malchere, A., Joly-Pottuz, L., Mowat, P., Lux, F., Tillement, O., Burdin, B., Rivoire, A., Boule, C., Anselme-Bertrand, I., Pourchez, J., Cottier, M., Roux, S., Rodriguez-Lafrasse, C. \& Perriat, P. Internalization pathways into cancer cells of gadolinium-based radiosensitizing nanoparticles. Biomaterials 34, 181-195 (2013).

17 Yi, X., Yang, K., Liang, C., Zhong, X., Ning, P., Song, G., Wang, D., Ge, C., Chen, C. Chai, Z. \& Liu, Z. Imaging-guided combined photothermal and radiotherapy to treat subcutaneous and metastatic tumors using iodine-131-doped copper sulfide nanoparticles. Adv. Funct. Mater. 25, 4689-4699 (2015).

18 Arambula, J. F., McCall, R., Sidoran, K. J., Magda, D., Mitchell, N. A., Bielawski, C. W., Lynch, V. M., Sessler, J. L. \& Arumugam, K. Targeting antioxidant pathways with ferrocenylated $\mathrm{N}$-heterocyclic carbene supported gold(I) complexes in A549 lung cancer cells. Chem. Sci. 7, 1245-1256 (2016).

19 Yang, Y., Chao, Y., Liu, J., Dong, Z., He, W., Zhang, R., Yang, K., Chen, M. \& Liu, Z. Core-shell and co-doped nanoscale metal-organic particles (NMOPs) obtained via postsynthesis cation exchange for multimodal imaging and synergistic thermo-radiotherapy. NPG Asia Mater. 9, e344 (2017).

20 Gao, X. Y., Zhang, J. S. \& Zhang, L. Hollow sphere selenium nanoparticles: their in-vitro anti hydroxyl radical effect. Adv. Mater. 14, 290-293 (2002).

21 Drake, E. N. Cancer chemoprevention: selenium as a prooxidant not an antioxidant. Med. Hypotheses 67, 318-322 (2006).

$22 \mathrm{Li}$, Y., Li, X., Wong, Y. S., Chen, T., Zhang, H., Liu, C. \& Zheng, W. The reversal of cisplatin-induced nephrotoxicity by selenium nanoparticles functionalized with 11 mercapto-1-undecanol by inhibition of ROS-mediated apoptosis. Biomaterials 32, 9068-9076 (2011).

23 Liu, T., Lai, L., Song, Z. \& Chen, T. A sequentially triggered nanosystem for precise drug delivery and simultaneous inhibition of cancer growth, migration, and invasion. Adv. Funct. Mater. 26, 7775-7790 (2016).

24 Jiang, W., Fu, Y., Yang, F., Yang, Y., Liu, T., Zheng, W., Zeng, L. \& Chen, T. Gracilaria lemaneiformispolysaccharide as integrin-targeting surface decorator of selenium nanoparticles to achieve enhanced anticancer efficacy. ACS Appl. Mater. Inter. 6, 13738-13748 (2014)

25 Yu, B., Liu, T., Du, Y., Luo, Z., Zheng, W. \& Chen, T. X-ray-responsive selenium nanoparticles for enhanced cancer chemo-radiotherapy. Colloids Surf. B Biointerfaces 139, 180-189 (2016)

26 Huang, Y., Luo, Y., Zheng, W. \& Chen, T. Rational design of cancer-targeted BSA protein nanoparticles as radiosensitizer to overcome cancer radioresistance. ACS Appl. Mater. Inter. 6, 19217-19228 (2014).

$27 \mathrm{He}$, L., Ji, S., Lai, H. \& Chen, T. Selenadiazole derivatives as theranostic agents for simultaneous cancer chemo-/radiotherapy by targeting thioredoxin reductase. J. Mater Chem. B 3, 8383-8393 (2015)

28 Deng, Z., Yu, L., Cao, W., Zheng, W. \& Chen, T. A selenium-containing ruthenium complex as a cancer radiosensitizer, rational design and the important role of ROSmediated signalling. Chem.Commun. 51, 2637-2640 (2015).

29 Ma, N., Xu, H., An, L., Li, J., Zhiwei, Z. \& Zhang, X. Radiation-sensitive diselenide block co-polymer micellar aggregates: toward the combination of radiotherapy and chemotherapy. Langmuir 27, 5874-5878 (2011).
30 Cao, W., Gu, Y., Meineck, M. \& Xu, H. The combination of chemotherapy and radiotherapy towards more efficient drug delivery. Chem. Asian J. 9, 48-57 (2014).

31 Zhang, S., Sun, C., Zeng, J., Sun, Q., Wang, G., Wang, Y., Wu, Y., Dou, S., Gao, M. \& $\mathrm{Li}, \mathrm{Z}$. Ambient Aqueous Synthesis of Ultrasmall PEGylated $\mathrm{Cu}_{2-\mathrm{x}} \mathrm{Se}$ Nanoparticles as a Multifunctional Theranostic Agent for Multimodal Imaging Guided Photothermal Therapy of Cancer. Adv Mater. 28, 8927-8936 (2016).

32 Ai, K., Liu, Y., Liu, J., Yuan, Q., He, Y. \& Lu, L. Large-scale synthesis of $\mathrm{Bi}_{2} \mathrm{~S}_{3}$ nanodots as a contrast agent for in vivo X-ray computed tomography imaging. Adv Mater. 23, 4886-4891 (2011).

33 Liu, J., Zheng, X. P., Yan, L., Zhou, L. J., Tian, G., Yin, W. Y., Wang, L. M., Liu, Y., Hu, Z. B., Gu, Z. J., Chen, C. Y. \& Zhao, Y. L. Bismuth sulfide nanorods as a precision nanomedicine for in vivo multimodal imaging-guided photothermal therapy of tumor. ACS Nano 9, 696-707 (2015).

34 Song, G., Liang, C., Gong, H., Li, M., Zheng, X., Cheng, L., Yang, K., Jiang, X. \& Liu, Z. Core-Shell $\mathrm{MnSe} @ \mathrm{Bi}_{2} \mathrm{Se}_{3}$ fabricated via a cation exchange method as novel nanotheranostics for multimodal imaging and synergistic thermoradiotherapy. Adv. Mater. 27, 6110-6117 (2015).

35 Li, Z., Hu, Y., Howard, K. A., Jiang, T., Fan, X., Miao, Z., Sun, Y., Besenbacher, F. \& Yu, M. Multifunctional bismuth selenide nanocomposites for antitumor thermochemotherapy and imaging. ACS Nano 10, 984-997 (2016).

36 Song, G., Liang, C., Yi, X., Zhao, Q., Cheng, L., Yang, K. \& Liu, Z. Perfluorocarbonloaded hollow $\mathrm{Bi}_{2} \mathrm{Se}_{3}$ nanoparticles for timely supply of oxygen under near-infrared light to enhance the radiotherapy of cancer. Adv. Mater. 28, 2716-2723 (2016).

37 Li, Z., Liu, J., Hu, Y., Howard, K. A., Li, Z., Fan, X., Chang, M., Sun, Y., Besenbacher, F., Chen, C. \& Yu, M. Multimodal imaging-guided antitumor photothermal therapy and drug delivery using bismuth selenide spherical sponge. ACS Nano 10, 9646-9658 (2016).

38 Mao, F. X., Wen, L., Sun, C. X., Zhang, S. H., Wang, G. L., Zeng, J. F., Wang, Y., Ma, J. M., Gao, M. Y. \& Li, Z. Ultrasmall biocompatible $\mathrm{Bi}_{2} \mathrm{Se}_{3}$ nanodots for multimodal imaging-guided synergistic radiophotothermal therapy against cancer. ACS Nano 10, 11145-11155 (2016).

39 Zhuang, A., Li, J. J., Wang, Y. C., Wen, X., Lin, Y., Xiang, B., Wang, X. P. \& Zeng, J. Screw-dislocation-driven bidirectional spiral growth of $\mathrm{Bi}_{2} \mathrm{Se}_{3}$ nanoplates. Angew Chem. Int. Ed. Engl. 53, 6425-6429 (2014).

40 Xia, Y., Qian, D., Hsieh, D., Wray, L., Pal, A., Lin, H., Bansil, A., Grauer, D., Hor, Y. S. Cava, R. J. \& Hasan, M. Z. Observation of a large-gap topological-insulator class with a single Dirac cone on the surface. Nat. Phys. 5, 398-402 (2009).

41 Zhang, X. D., Chen, J., Min, Y., Park, G. B., Shen, X., Song, S. S., Sun, Y. M., Wang, H., Long, W., Xie, J. P., Gao, K., Zhang, L. F., Fan, S. J., Fan, F. Y. \& Jeong, U. Metabolizable $\mathrm{Bi}_{2} \mathrm{Se}_{3}$ nanoplates: biodistribution, toxicity, and uses for cancer radiation therapy and imaging. Adv. Funct. Mater. 24, 1718-1729 (2014).

42 Cai, X., Wang, C., Yu, W., Fan, W., Wang, S., Shen, N., Wu, P., Li, X. \& Wang, F. Selenium exposure and cancer risk: an updated meta-analysis and meta-regression. Sci. Rep. 6, 19213 (2016)

43 Xie, H., Li, Z., Sun, Z., Shao, J., Yu, X. F., Guo, Z., Wang, J., Xiao, Q., Wang, H., Wang, Q. Q., Zhang, H. \& Chu, P. K. Metabolizable ultrathin $\mathrm{Bi}_{2} \mathrm{Se}_{3}$ nanosheets in imagingguided photothermal therapy. Small 12, 4136-4145 (2016).

44 Liu, W., Li, X. L., Wong, Y. S., Zheng, W. J., Zhang, Y. B., Cao, W. Q. \& Chen, T. F. Selenium nanoparticles as a carrier of 5 -fluorouracil to achieve anticancer synergism. ACS Nano 6, 6578-6591 (2012).

45 Huang, Y., He, L., Liu, W., Fan, C., Zheng, W., Wong, Y. S. \& Chen, T. Selective cellular uptake and induction of apoptosis of cancer-targeted selenium nanoparticles. Biomaterials 34, 7106-7116 (2013).

46 Chen, T. \& Wong, Y. S. Selenocystine induces caspase-independent apoptosis in MCF-7 human breast carcinoma cells with involvement of p53 phosphorylation and reactive oxygen species generation. Int. J. Biochem. Cell Biol. 41, 666-676 (2009).

47 Huang, P., Rong, P., Lin, J., Li, W., Yan, X., Zhang, M. G., Nie, L., Niu, G., Lu, J., Wang, W. \& Chen, X. Triphase interface synthesis of plasmonic gold bellflowers as nearinfrared light mediated acoustic and thermal theranostics. J. Am. Chem. Soc. 136, 8307-8313 (2014).

48 Min, Y., Moon, G. D., Kim, B. S., Lim, B., Kim, J. S., Kang, C. Y. \& Jeong, U. Quick, controlled synthesis of ultrathin $\mathrm{Bi}_{2} \mathrm{Se}_{3}$ nanodiscs and nanosheets. J. Am. Chem. Soc. 134, 2872-2875 (2012).

49 Fan, Y. L., Wang, W. H., Song, W., Chen, H. S., Teng, A. G. \& Liu, A. J. Partial characterization and anti-tumor activity of an acidic polysaccharide from Gracilaria lemaneiformis. Carbohyd. Polym. 88, 1313-1318 (2012).

50 Butterworth, K. T., McMahon, S. J., Currell, F. J. \& Prise, K. M. Physical basis and biological mechanisms of gold nanoparticle radiosensitization. Nanoscale 4, 4830-4838 (2012).

51 Retif, P., Pinel, S., Toussaint, M., Frochot, C., Chouikrat, R., Bastogne, T. \& BarberiHeyob, M. Nanoparticles for radiation therapy enhancement: the key parameters. Theranostics 5, 1030-1045 (2015).

52 Wang, N., Feng, Y., Zeng, L., Zhao, Z. \& Chen, T. Functionalized multiwalled carbon nanotubes as carriers of ruthenium complexes to antagonize cancer multidrug resistance and radioresistance. ACS Appl. Mater. Inter. 7, 14933-14945 (2015).

53 Desgrosellier, J. S. \& Cheresh, D. A. Integrins in cancer: biological implications and therapeutic opportunities. Nat. Rev. Cancer 10, 9-22 (2010).

54 Maus, L., Dick, O., Bading, H., Spatz, J. P. \& Fiammengo, R. Conjugation of peptides to the passivation shell of gold nanoparticles for targeting of cell-surface receptors. ACS Nano. 4, 6617-6628 (2010).

55 Yang, D., Zhao, Y. C., Li, A. Y., Wang, S. M., Wang, G. X. \& Sun, Y. Smac-mimetic compound SM-164 induces radiosensitization in breast cancer cells through activation 
of caspases and induction of apoptosis. Breast Cancer Res. Treat. 133, 189-199 (2012)

56 Zhou, W., Wang, X. Y., Hu, M., Zhu, C. C. \& Guo, Z. J. A mitochondrion-targeting copper complex exhibits potent cytotoxicity against cisplatin-resistant tumor cells through multiple mechanisms of action. Chem. Sci. 5, 2761-2770 (2014).

57 Fernandez-Gallardo, J., Elie, B. T., Sadhukha, T., Prabha, S., Sanau, M., Rotenberg, S. A., Ramos, J. W. \& Contel, M. Heterometallic titanium-gold complexes inhibit renal cancer cells in vitro and in vivo. Chem. Sci. 6, 5269-5283 (2015).

58 Wang, H., Yang, X., Shao, W., Chen, S., Xie, J., Zhang, X., Wang, J. \& Xie, Y. Ultrathin black phosphorus nanosheets for efficient singlet oxygen generation. J. Am. Chem. Soc. 137, 11376-11382 (2015)

59 Dong, X. W., Zhang, Z., Zhao, J. D., Lei, J., Chen, Y. Y., Li, X., Chen, H. H., Tian, J. L., Zhang, D., Liu, C. R. \& Liu, C. L. The rational design of specific SOD1 inhibitors via copper coordination and their application in ROS signaling research. Chem. Sci. 7, 6251-6262 (2016).

60 DeRosa, M. C. \& Crutchley, R. J. Photosensitized singlet oxygen and its applications. Coord. Chem. Rev. 233, 351-371 (2002).

61 Luo, Y., Li, X. L., Chen, T. F., Wang, Y. \& Zheng, W. J. Synthesis of a novel thiophene derivative that induces cancer cell apoptosis through modulation of AKT and MAPK pathways. MedChemComm. 3, 1143-1146 (2012).

62 Sharlow, E. R., Leimgruber, S., Lira, A., McConnell, M. J., Norambuena, A., Bloom, G. S., Epperly, M. W., Greenberger, J. S. \& Lazo, J. S. A small molecule screen exposes mTOR signaling pathway involvement in radiation-induced apoptosis. ACS Chem. Biol. 11, 1428-1437 (2016).

63 He, L., Huang, Y., Zhu, H., Pang, G., Zheng, W., Wong, Y.-S. \& Chen, T. Cancertargeted monodisperse mesoporous silica nanoparticles as carrier of ruthenium polypyridyl complexes to enhance theranostic effects. Adv. Funct. Mater. 24 2754-2763 (2014).

64 Ngwa, W., Korideck, H., Kassis, A. I., Kumar, R., Sridhar, S., Makrigiorgos, G. M. \& Cormack, R. A. In vitro radiosensitization by gold nanoparticles during continuous low-doserate gamma irradiation with I-125 brachytherapy seeds. Nanomedicine 9, 25-27 (2013).

65 Huang, P., Lin, J., Li, W. W., Rong, P. F., Wang, Z., Wang, S. J., Wang, X. P., Sun, X. L., Aronova, M., Niu, G., Leapman, R. D., Nie, Z. H. \& Chen, X. Y. Biodegradable gold nanovesicles with an ultrastrong plasmonic coupling effect for photoacoustic imaging and photothermal therapy. Angew Chem. Int. Ed. Engl. 52, 13958-13964 (2013).

66 Chen, M., Tang, S. H., Guo, Z. D., Wang, X. Y., Mo, S. G., Huang, X. Q., Liu, G. \& Zheng, N. F. Core-shell Pd@Au nanoplates as theranostic agents for in vivo photoacoustic imaging, CT imaging, and photothermal therapy. Adv. Mater 26, 8210-8216 (2014)

67 Song, J. B., Yang, X. Y., Jacobson, O., Lin, L. S., Huang, P., Niu, G., Ma, Q. J. \& Chen, $X$. Y. Sequential drug release and enhanced photothermal and photoacoustic effect of hybrid reduced graphene oxide-loaded ultrasmall gold nanorod vesicles for cancer therapy. ACS Nano 9, 9199-9209 (2015).

68 Liu, T., Shi, S. X., Liang, C., Shen, S. D., Cheng, L., Wang, C., Song, X. J., Goel, S., Barnhart, T. E., Cai, W. B. \& Liu, Z. Iron oxide decorated $\mathrm{MoS}_{2}$ nanosheets with double PEGylation for chelator-free radio labeling and multimodal imaging guided photothermal therapy. ACS Nano 9, 950-960 (2015).

69 Yu, J., Yang, C., Li, J. D. S., Ding, Y. C., Zhang, L., Yousaf, M. Z., Lin, J., Pang, R., Wei, L. B., Xu, L. L., Sheng, F. G., Li, C. H., Li, G. J., Zhao, L. Y. \& Hou, Y. L. Multifunctional $\mathrm{Fe}_{5} \mathrm{C}_{2}$ nanoparticles: a targeted theranostic platform for magnetic resonance imaging and photoacoustic tomography-guided photothermal therapy. Adv. Mater 26, 4114-4120 (2014)

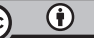

This work is licensed under a Creative Commons Attribution 4.0 International License. The images or other third party material in this article are included in the article's Creative Commons license, unless indicated otherwise in the credit line; if the material is not included under the Creative Commons license, users will need to obtain permission from the license holder to reproduce the material. To view a copy of this license, visit http:// creativecommons.org/licenses/by/4.0/

(C) The Author(s) 2017

Supplementary Information accompanies the paper on the NPG Asia Materials website (http://www.nature.com/am) 